\title{
A Human-Immune-System (HIS) humanized mouse model (DRAGA: HLA-A2. HLA-DR4. Rag1 KO.IL-2R $\gamma$ C KO. NOD) for COVID-19
}

Teodor-D. Brumeanu*1, Pooja Vir ${ }^{¥ 1}$, Ahmad Faisal Karim ${ }^{* 1}$, Swagata Kar ${ }^{3}$, Dalia Benetiene ${ }^{3}$, Megan Lok ${ }^{3}$, Jack Greenhouse ${ }^{3}$, Tammy Putmon-Taylor ${ }^{3}$, Christopher Kitajewski ${ }^{3}$, Kevin K. Chung $^{1}$, Kathleen P. Pratt ${ }^{1}$, Sofia A. Casares ${ }^{* 1,2}$

${ }^{1}$ Uniformed Services University of the Health Sciences, Department of Medicine, Division of Immunology, Bethesda, MD 20814, U.S.A.

${ }^{2}$ Naval Medical Research Center/Walter Reed Army Institute of Research, Infectious Diseases Directorate, Silver Spring, MD 20910, U.S.A.

${ }^{3}$ Bioqual Inc., Rockville, MD 20852, U.S.A.

${ }^{*}$ Corresponding authors: T-D. B (Teodor-doru.brumeanu@usuhs.edu) and S.C. (sofia.a.casares.civ@mail.mil). ${ }^{*}$ P.V. and A.F.K. contributed equally to this work.

Keywords: SARS-CoV-2, HIS-humanized mouse model, COVID-19, lung immunopathology.

\author{
Abstract: $135 / 150$ \\ Intro, Results, Discussion: 2,926/3,000 \\ \# Figures: 6 \\ \#References: 59 \\ \# Supplemental Figures: 12 \\ Supplemental Tables: 1
}




\begin{abstract}
We report the first Human Immune System (HIS)-humanized mouse model ("DRAGA": HLA-A2.HLA-DR4.Rag1KO.IL-2R $\gamma$ CKO.NOD) for COVID-19 research. This mouse is reconstituted with human cord blood-derived, HLA-matched hematopoietic stem cells. It engrafts human epi/endothelial cells expressing the human ACE2 receptor for SARS-CoV2 and TMPRSS2 serine protease co-localized on lung epithelia. HIS-DRAGA mice sustained SARS-CoV-2 infection, showing deteriorated clinical condition, replicating virus in the lungs, and human-like lung immunopathology including T-cell infiltrates, microthrombi and pulmonary sequelae. Among T-cell infiltrates, lung-resident (CD103 ${ }^{+}$) $\mathrm{CD8}^{+} \mathrm{T}$ cells were sequestered in epithelial $\left(\mathrm{CD}_{2} 6^{+}\right)$lung niches and secreted granzyme B and perforin, indicating cytotoxic potential. Infected mice also developed antibodies against the SARSCoV-2 viral proteins. Hence, HIS-DRAGA mice showed unique advantages as a surrogate in vivo human model for studying SARS-CoV-2 immunopathology and for testing the safety and efficacy of candidate vaccines and therapeutics.
\end{abstract}


Infection with Severe Acute Respiratory Syndrome-coronavirus-2 (SARS-CoV-2), the highly transmissible pathogen responsible for the ongoing pandemic coronavirus disease 2019 (COVID-19), results in outcomes from asymptomatic or mild disease to severe pneumonia and acute respiratory distress syndrome in the human population ${ }^{1-4}$. Many severe COVID-19 patients experience a hyper-inflammatory response ("cytokine storm") ${ }^{5}$ combined with dysregulated coagulation ${ }^{6-12}$. Both SARS-CoV-2 and the related SARS-CoV-1 coronavirus fuse with and enter cells following engagement of their surface spike (S) protein with human angiotensin-converting enzyme 2 (hACE2) ${ }^{13-15}$, which associates with type II transmembrane serine protease (TMPRSS2) on multiple epi/endothelial tissues and vasculature, including in the lung, liver, colon, esophagus, small intestine, duodenum, kidney, brain, and tongue ${ }^{16,17}$. TMPRSS2 increases viral uptake by cleaving the S protein, thereby facilitating fusion of the $S$ protein receptor binding domain (RBD) with hACE2 on epi/endothelial cells ${ }^{13}$.

Appropriate, clinically relevant animal models are required to evaluate mechanisms of human-like pathogenesis following SARS-CoV-2 infection and as platforms for rapid testing of vaccines and potential therapeutics. The SARS-CoV-2 S protein has lower affinity for murine (m)ACE2 than for hACE2 ${ }^{15}$, and accordingly, mice are not susceptible to infection by coronaviruses that utilize this receptor. To overcome this limitation, several murine strains transgenic (Tg) for hACE2 expression driven by various promoters have been generated to facilitate coronavirus research. Overall, these murine models have shown different tropisms, viral loads and pathologies following infection ${ }^{18-21}$. Hence, a human immune system (HIS)humanized animal model expressing hACE2 that is permissive for SARS-CoV-2 infection would be a highly appealing model to study mechanisms of viral entry and human-like anti-viral immune responses. Challenges in developing HIS-mouse models that mimic the human immune system with high fidelity include poor engraftment of hematopoietic stem cells, inefficient human cell expansion and homeostasis, insufficient numbers of reconstituted human 
T or B cells, sub-optimal B-cell development, lack of immunoglobulin class switching, acute/chronic GVHD, and lack of HLA class I and/or II T-cell restriction ${ }^{22,23}$. Furthermore, restrictions on the use of human fetal tissue for research (https://oir.nih.gov/sourcebook/ethicalconduct/special-research-considerations/policies-procedures-use-human-fetal-tissue-hftresearch-purposes-intramural/policies) has focused attention on alternative donor cell sources, such as umbilical cord blood.

The HIS-humanized DRAGA (HLA-DR4.HLA-A2.1.IL-2R $\gamma \mathrm{C}$ KO.RAG1 KO.NOD) mouse strain is devoid of many of the above limitations ${ }^{24,25}$. These mice are HIS-reconstituted after irradiation by infusion with hematopoietic stem cells from HLA-matched umbilical cord blood. They lack the murine adaptive immune system while expressing a long-lived functional HIS. They respond vigorously by specific $\mathrm{T}$ and $\mathrm{B}$ cell responses to infection or immunization with various pathogens including malaria protozoans, HIV, ZIKA, Scrub Typhus, and Influenza type A heterosubtypes $^{26-31}$. They also engraft various hematopoietic cell-derived human cells, including endothelial cells (EDs) in the liver ${ }^{26}$ and both epithelial cells (ECs) and EDs in the lungs ${ }^{28,29}$.

Herein, we demonstrate that HIS-DRAGA mice naturally express hACE2 and hTMPRSS2 on engrafted human epi/endothelial cells on several organs, including the lungs. Importantly, these mice sustained intranasal infection with SARS-CoV-2 for at least 25 days and developed dosedependent, mild to severe human-like lung immunopathology. We suggest that the HIS-DRAGA mouse is an excellent and convenient model for studying mechanisms of SARS-CoV-2 infection and human-like anti-SARS-CoV-2 immune responses, and for testing the safety and efficacy of novel vaccines and therapeutics. 


\section{Results}

HIS-DRAGA mice naturally express hACE2 and hTMPRSS2. Human ACE2 mRNA was detected in the lungs of non-infected, HIS-reconstituted DRAGA mice (mice $a-j$, Table S1) but not of non-reconstituted mice, whereas mACE2 mRNA was detected in both HIS-reconstituted and non-reconstituted DRAGA mouse lungs (Fig. 1a). A recombinant SARS-CoV-2 S1(RBD)mouse Fc $2 \mathrm{2a}$ chimeric protein ( $\mathrm{S} 1(\mathrm{RBD})-\mathrm{mFc} \gamma 2 \mathrm{a})$ and magnetic beads coated with rat antimouse IgG2a were used to immunoprecipitate hACE2 from pooled lung homogenates of HISreconstituted DRAGA mice $(n=10)$, non-HIS reconstituted DRAGA mice $(n=10)$ and a human lung tissue lysate. Quantitative hACE2 ELISA measurements indicated hACE2 was 7.8X less abundant in HIS-DRAGA mouse lungs than in the human lung sample, while no hACE2 was detected in immunoprecipitates from non-HIS reconstituted DRAGA mouse lungs (Fig. S1). The molecular weight of hACE2 expressed in lungs of HIS-DRAGA mice was identical to that in human lungs as shown by Western Blot (Fig. S1). To visualize hACE2 protein expression, immunofluorescence microscopy was carried out on lung sections probed with S1(RBD)$\mathrm{mF} \gamma 2 \mathrm{2a}$. Digitized images revealed hACE2 expression on alveolar and bronchiolar epithelia (Fig. 1b), while very weak or no staining was detected in lung sections from non-HIS reconstituted mice (Fig. 1c). Immunofluorescence staining also revealed that hTMPRSS2 was co-localized with hACE2 on the bronchiolar epithelia and on endothelial walls of pulmonary arterioles (Fig.1d).

We next questioned whether human (h)CD326, a specific marker of lung ECs, is also expressed on engrafted hECs. Co-staining with anti-hCD326-PE and S1(RBD)-mFc $22 a$ revealed co-localization of hACE2 and hCD326 in lungs of HIS-reconstituted (Fig. S2, upper and middle panels) but not non-reconstituted DRAGA mice (Fig. S2, lower pane/s). Staining of sections from liver, kidneys, small intestine and brain of HIS-DRAGA mice with S1(RBD)- 
mFc 2 2a revealed hACE2 expression on liver endothelia (Fig. S3), epi/endothelia of proximal and distal convoluted tubules and small arterioles surrounding the podocytes in the kidney glomeruli (Fig. S4), columnar epithelia of the absorptive intestinal villi (Fig. S5), and the white matter, granular layer and Purkinje cells in the cerebellum cortex (Fig. S6). Expression of hACE2 on epi/endothelia of these organs was further confirmed by probing the tissue sections with a mouse anti-hACE2 antibody (Fig. S7).

HIS-DRAGA mice can sustain SARS-CoV-2 infection. In the first infection experiment, three HIS-DRAGA mice were infected intranasally with relatively high doses of virus in $50 \mu l$ saline, $25 \mu \mathrm{l}$ per nostril: $2.8 \times 10^{4}$ pfu (male \#M1 + female \#F1) and $2.8 \times 10^{3}$ pfu (female \#F2). While the male mouse succumbed 24 hours after infection, both female mice sustained the infection until the experimental endpoint of 14 days post-infection (dpi) (Fig. 2a). These mice showed an abrupt loss in body weight (likely due to severe dehydration), ruffed fur, hunched back, and reduced mobility starting at $1 \mathrm{dpi}$. Mouse \#F2 regained its original weight and mobility by $9 \mathrm{dpi}$, while mouse \#F1 was still 10\% below its original weight at $14 \mathrm{dpi}$, when they were both euthanized.

In the second infection experiment, 8 HIS-DRAGA female mice (\#F3-F10) were inoculated i.n. with a lower dose of SARS-CoV-2 virus $\left(10^{3} \mathrm{pfu} / \mathrm{mouse}\right)$, and their body weights and clinical condition were monitored daily for 25 days (Fig. 2b). All mice in this group lost $5 \%-15 \%$ of their weight and showed deteriorating conditions (ruffed fur, hunched back, reduced mobility) starting at 1 dpi. However, mice \#F3 and \#F4 recovered their initial body weights by 7 and 25 dpi, respectively, while the remaining mice survived the infection but had still not recovered their initial body weights at the experimental endpoint ( $25 \mathrm{dpi})$, when they were euthanized for further analyses. 
In the third infection experiment, 3 HIS-DRAGA females and 3 HIS-DRAGA males (\#F11-F13 and \#M2-M4, Table S1) were infected i.n. with SARS-CoV-2 $\left(10^{3}\right.$ pfu/mouse $)$ and their body mass and clinical condition were monitored daily. Five of these 6 mice showed weight loss starting at 1 dpi (Fig. 2c) and all showed ruffed fur, hunched back and reduced mobility. The mice were sacrificed at $4 \mathrm{dpi}$, and the viral loads in their lungs were quantified (Fig. 2 d).

\section{SARS-CoV-2 infected HIS-DRAGA mice display severe, human-like lung}

pathology. Patients infected with SARS-CoV-2 have been shown to exhibit varying degrees of lung pathology that correlate with the viral load in their lungs ${ }^{1-4}$. As in recent reports based on human autopsies ${ }^{32-34}$, and in contrast to the non-infected mice (Fig. 3a), H\&E and Masson's trichrome staining of lung sections from mice infected with high doses of SARS-CoV-2 virions showed multiple interstitial, peripheral, and peri-bronchiolar infiltrates (Fig. 3b). These were more noticeable in the lungs of mouse \#F1, which was infected with the highest dose of virus $\left(2.8 \times 10^{4} \mathrm{pfu}\right)$ and had not recovered its initial body weight by $14 \mathrm{dpi}$ than in mouse \#F2, which was infected with $2.8 \times 10^{3} \mathrm{pfu}$, (Fig. S8). Mouse \#F1 also developed multiple intra-alveolar and intra-arteriolar microthrombi adherent to the endovasculature (Fig. 3c, d) that stained positive for the platelet marker CD61 (glycoprotein IIla) (Figs. S9 and S10), as well as intra-bronchiolar blood clots (Fig. 3e) and interstitial hemorrhagic patches (Fig. 3f).

Lung tissues from female HIS-DRAGA mice infected i.n. with the lowest dose of virus $\left(10^{3}\right.$ pfu/mouse, second experiment) were analyzed histologically at the experimental endpoint (25 dpi). Morphological analysis of lungs from mice \#F3 and \#F4, which recovered their initial body weights by 7 and 25 dpi, respectively, showed small discolored areas and dispersed interstitial infiltrates throughout the lung parenchyma (Fig. $\mathbf{3 g}$ ). In contrast, the mice that had not 
recovered their initial body weights by $25 \mathrm{dpi}$, e.g., mouse \#F5, showed large pulmonary discoloration and heavily infiltrated areas (Fig. 3h) and incipient collagen-based fibrosis in perialveolar infiltrated areas (Figs. $\mathbf{3 g}$ and $\mathbf{S 1 0}$ ). Similar to mouse \#F1 that was infected with $2.8 \times 10^{4} \mathrm{pfu}$ in the first experiment (Fig. 3f), mouse \#F5 showed interstitial hemorrhagic patches in the lungs (Fig. 3h) and a more advanced process of pulmonary fibrosis (Fig. S11).

\section{Pulmonary infiltrates in SARS-CoV-2 infected HIS-DRAGA mice contained lung- resident human T cells expressing activation markers. Infiltrates visualized in lung} sections from SARS-CoV-2-infected mice stained positive for hCD45 indicating human lymphocytes (Fig. 4a,c) and hCD3 indicating human T cells (Fig. 4b,d), as we previously described in non-infected HIS-humanized DRAGA mice ${ }^{24,25}$. Interestingly, some of the human $\mathrm{CD}^{+} \mathrm{T}$-cell infiltrates in mice infected with a relatively high SARS-CoV-2 dose $\left(2.8 \times 10^{3} \mathrm{pfu}\right)$ looked fairly organized (Fig. 4d). Both hCD8 ${ }^{+}$and hCD4 ${ }^{+}$T-cell subsets were found sequestered in alveolar CD326 ${ }^{+}$hECs, with some egressing into the alveolar air space (Fig. 5). Alveolar hCD326 ${ }^{+} \mathrm{hEC}$ contained larger clusters of hCD8 ${ }^{+} \mathrm{T}$ cells than $\mathrm{hCD} 4^{+} \mathrm{T}$ cells. Human $\mathrm{CD}^{+} \mathrm{T}$ cells that co-localized with $\mathrm{hCD} 326^{+} \mathrm{ECs}$ also stained positive for CD103, a marker for lung T-cell residency ${ }^{35,36}$ (Fig. 6). Among the $\mathrm{CD}^{+} \mathrm{T}$ cells sequestered in alveolar EC niches, many stained positive for perforin and granzyme B, indicating potential cytotoxic activity (Fig. 6).

\section{HIS-DRAGA mice infected with SARS-CoV-2 mounted specific antibody}

responses to SARS-CoV-2 viral proteins. ELISA results obtained using plates coated with recombinant SARS-CoV-2 S1(RBD), S1-trimer or N proteins were used to measure specific antibodies in serum samples derived from infected mice. Mouse \#F2 from the first experiment, which was infected with $2.8 \times 10^{3}$ pfu and recovered its initial body weight by $9 \mathrm{dpi}$, developed lung-resident $\left(\mathrm{CD} 103^{+}\right) \mathrm{hCD}^{+} \mathrm{T}$ cells (Fig. 6) but did not have detectable S1(RBD)-specific 
hlgM antibodies at $14 \mathrm{dpi}$ (not shown). In contrast, mouse \#F1, which was infected with $2.8 \times 10^{4}$ pfu and had not recovered its body weight by $14 \mathrm{dpi}$, developed S1(RBD)-specific hlgM antibodies, but had fewer clusters of lung-resident hCD8 ${ }^{+} \mathrm{T}$ cells (not shown). Furthermore, the second infection experiment using a lower dose of SARS-CoV-2 virions $\left(10^{3} \mathrm{pfu}\right)$ and a longer follow-up period ( $25 \mathrm{dpi}$ ), revealed that all mice developed hlgM and hlgG antibody responses to the spike and nucleocapsid (N) viral proteins (Fig. S12). Of note, the mice that recovered their initial body weights, \#F3 and \#F4, mounted the strongest hlgG responses to S1(RBD), Strimer and $\mathrm{N}$ viral proteins.

Together, these results have demonstrated that pluripotent human $\mathrm{CD} 34^{+}$human stem cells from umbilical cord blood differentiated not only into functional human T and B cells, but also into human ECs and EDs expressing hACE2 and hTMPRSS2 in several organs of HIS-DRAGA mice. HIS-DRAGA mice sustained infection with SARS-CoV-2 for at least 3 weeks, exhibiting clinical symptoms, with some recovering from the infection. Evaluations of their organ tissues have also revealed pathological events including parenchymal and peripheral lung $\mathrm{CD}^{+}{ }^{+}$-cell infiltrates, intra-alveolar and intra-arteriolar microthrombi adherent to the endovasculature, intrabronchiolar blood clots and incipient pulmonary sequelae. Lung-resident (CD103 $\left.{ }^{+}\right) \mathrm{CD}^{+}$ secreting granzyme B and perforin, and $\mathrm{CD}^{+} \mathrm{T}$ cells have been visualized in $\mathrm{CD} 326^{+}$epithelial lung niches of infected HIS-DRAGA mice, as previously shown in influenza-infected human lung tissue $\mathrm{e}^{35,36}$.

\section{Discussion}

The HIS-humanized DRAGA mouse expresses a sustained, fully functional human immune system. In the present study, we found that reconstituted HIS-DRAGA mice engraft human epi/endothelial cells expressing hACE2, the primary receptor for SARS-CoV-2 and its 
associated serine protease, hTMPRSS2, in multiple organs. Recent studies have revealed that ACE2 is widely expressed in human tissues ${ }^{37}$.

We have demonstrated that HIS-DRAGA mice can be readily infected via the intranasal route with non-mouse-adapted SARS-CoV-2 and that the infection is sustained for at least 25 days. Infected mice developed mild to severe lung immunopathology including T-cell infiltrates, alveolar damage, intra-alveolar and intra-arteriolar microthrombi, bronchiolar blood clots and collagen deposition in the lungs. Severely infected HIS-DRAGA mice recapitulated many of the diverse pathological events in COVID-19 patients involving lungs ${ }^{1-4,38}$, liver ${ }^{39}$, gastro-intestinal track $^{40}$, kidneys ${ }^{41}$, central nervous system ${ }^{42}$, heart ${ }^{43}$ and genitourinary system ${ }^{44}$. As in recent analyses of autopsy samples from COVID-19 patients $^{32}$, the lung infiltrates of infected HISDRAGA mice were interstitial and grouped around terminal bronchioles and peripheral parenchyma. They contained lung-resident $\left(\mathrm{CD}_{103^{+}}\right)$human T cells, particularly $\mathrm{CD} 8^{+} \mathrm{T}$ cells clustered in $\mathrm{CD}_{326}{ }^{+}$lung epithelial niches that stained positive for granzyme B and perforin, indicating the presence of functional cytotoxic T cells. The presence of CD4 ${ }^{+}$and $\mathrm{CD} 8^{+} \mathrm{T}$ cells reactive to the ORF-1 and NP proteins of SARS-CoV-2 virus in convalescent COVID-19 patients was reported recently ${ }^{45}$. Some granzyme ${ }^{+}$and perforin ${ }^{+}$lung-resident $\mathrm{CD}^{+}$human $\mathrm{T}$ cells visualized in the infected HIS-DRAGA mice egressed into the alveolar air space. Lung-resident $\mathrm{CD}^{+} \mathrm{T}$ cells have been detected and characterized in mice, monkeys and humans ${ }^{46,47}$. This cell subset is positioned to act at the frontline of lung epithelial mucosa after a primary viral respiratory infection to provide rapid and efficient cross-protection against subsequent exposures to respiratory viruses ${ }^{46-51}$.

Interestingly, clusters of lung-resident $\mathrm{CD}^{+} \mathrm{T}$ cells were more profuse in the infected mouse (\#F2) that recovered its body weight early after infection with a relatively high dose of CoV-2 virions $\left(2.8 \times 10^{3} \mathrm{pfu}\right)$ but showed no detectable S1(RBD)-specific hlgM at $14 \mathrm{dpi}$. In contrast, 
mouse \#F1, which was infected with $2.8 \times 10^{4}$ pfu and had not recovered its body weight at 14 dpi, developed S1(RBD)-specific hlgM antibodies and showed fewer human lung-resident T cells. Furthermore, two of the mice infected with $10^{3}$ pfu recovered their initial body weights by 7 and 25 dpi (\#F3 and \#F4, respectively), and these mice developed the highest titers of hlgG antibodies to the Spike(S) and Nucleocapsid (N) proteins. They also showed more profuse clusters of lung-resident $\left(\mathrm{CD} 103^{+}\right) \mathrm{hCD}^{+} \mathrm{T}$ cells (not shown) as compared with mice that did not recover from the infection. These findings raised a question that needs to be further addressed: are antibodies, lung-resident $\mathrm{CD} 8^{+} \mathrm{T}$ cells, or both critical for efficient protection against COVID-19? Recent studies in animal models and humans have suggested critical roles for both antibodies ${ }^{52-54}$ and T cells ${ }^{55}$ for protection against COVID-19. Another subject for future research is the possibility of natural transmission of SARS-CoV-2 infection among mice. We recently demonstrated such transmission of influenza between co-caged, infected and noninfected HIS-DRAGA mice ${ }^{31}$. While investigation of the dynamics of antibody titers and virus clearance in COVID-19 patients is feasible in humans, exploring the dynamics of lung-resident $\mathrm{CD}^{+} \mathrm{T}$ cells in infected human subjects is not, as studies of human lungs are restricted to analyses of single biopsy/resection or post-autopsy samples.

We also found that the SARC-CoV-2 infected HIS-DRAGA mouse are able to mount fully human IgM and IgG antibody responses to the viral proteins, e.g., S1(RBD), trimeric $\mathrm{S}$ and $\mathrm{N}$ proteins, some of which may have translational potential. While high antibody titers to the $\mathrm{S} 1(\mathrm{RBD})$ viral protein correlated with body weight recovery following infection, i.e. with less severe infection, the antibody titers to the Nucleocapsid $(\mathrm{N})$ protein did not.

Thrombophilia, including microthrombi in the lung, sometimes termed "immunothrombi" due to their association with the hyperinflammatory response, are a feature of severely infected COVID-19 patients. Histologic analysis of pulmonary vessels from COVID-19 autopsy samples 
showed widespread thrombosis with microangiopathy $6,7,9,10$. In lungs, new vessel growth occurs predominantly through a mechanism of intussusceptive angiogenesis ${ }^{56}$. In addition, occlusion of alveolar capillaries described in patients with severe COVID-19 ${ }^{11}$ and adherence of microthrombi to the vascular endothelium suggest a distinctive angiocentric feature ${ }^{6,11}$. Lungs of infected HIS-DRAGA mice had clusters of non-nucleated cells staining positive for CD61, consistent with the presence of platelets and microthrombi in the alveolar air space. Infected mice also showed hemorrhagic patches in the lungs, mimicking those described in autopsy samples from humans exiting COVID-1932.

Pulmonary fibrosis, also known as sequelae, indicates tissue scarring during healing that occurs by deposition of collagen in heavily infiltrated areas, as revealed in lungs from patients recovering from severe respiratory infections. Radiographic and autopsy data have identified pulmonary fibrosis not only in COVID-19, but also in SARS CoV-1 and MERS ${ }^{57}$. It has been suggested that collagen deposition in severe lung injury by SARS viruses relies primarily on trafficking circulating fibrocytes to the lung $^{58}$ and increased signaling through the epidermal growth factor receptor $^{59}$. Masson's Trichrome staining of lung sections from SARS-CoV-2infected mice that survived high-viral-dose infection, and from some mice that sustained lowdose infection for up to 25 days, revealed incipient collagen depositions in heavily infiltrated alveoli and surrounding the bronchioles.

In summary, HIS-DRAGA mice, infected with a non-mouse adapted strain of SARS-CoV-2 were able to sustain the infection for at least 25 days, recapitulated major immunopathological events described in COVID-19 patients, and mounted human cellular and humoral responses to the SARS-CoV-2 proteins. This HIS-humanized in vivo surrogate mouse model offers compelling advantages for studying the mechanisms of SARS-CoV-2 infection and human immunopathology of COVID-19 disease, notably the ability to analyze physiological responses 
and harvest tissues at specific time points following infections and subsequent viral challenges.

This mouse model should also prove useful for efficient preclinical testing of both safety and efficacy of vaccines and potential therapeutics for human COVID-19.

Data and animal availability: Additional datasets generated and/or analyzed during the current study are available from the corresponding authors on reasonable request.

\section{Acknowledgements}

We acknowledge support from the Collaborative Health Initiative Research Program at Uniformed Services University, Bethesda, MD (K.P.P), the Department of Medicine, Sanford Endowment intramural funds (T-D.B. and K.P.P.), the Military Infectious Diseases Research Program (S.C.), and NHLBI HL 130448 and HL 12767B (K.P.P).

We thank Soumya Sashikumar for maintaining DRAGA mice colony at NMRC. The study protocol was reviewed and approved by the Bioqual Institutional Animal Care and Use Committee (\#20-019P) and by the Walter Reed Army Institute of Research/Naval Medical Research Center Institutional Animal Care and Use Committee (\#19-IDD-24) in compliance with all applicable federal regulations governing the protection of animals and research. T-D.B, KPP, KKC and SC are federal employees and this work was conducted as part of their official duties.

The opinions or assertions contained herein are the private ones of the authors and are not to be construed as official or reflecting the views of the Department of Defense or the Uniformed Services University of the Health Sciences. 


\section{Author contributions}

T-DB, SC, KPP and KKC conceived and guided the study. T-DB, SC, PV and AFK performed experiments. T-DB, SC and KPP analyzed data and wrote the paper, with input from PV and AFK. SK, DB, ML, JG, TP-T and CK oversaw or conducted the experiments at the BSL-3 facility at Bioqual, Inc. (Rockville, MD, USA): infecting and monitoring the clinical condition of mice, extracting lung tissues, and measuring lung viral loads by RT-qPCR. All authors approved the content of the manuscript. 


\section{References}

1. Zhou, P. et al. A pneumonia outbreak associated with a new coronavirus of probable bat origin. Nature 579, 270-273 (2020).

2. Jiang, F. et al. Review of the Clinical Characteristics of Coronavirus Disease 2019 (COVID-19). J Gen Intern Med 35, 1545-1549 (2020).

3. Ye, Z., Zhang, Y., Wang, Y., Huang, Z. \& Song, B. Chest CT manifestations of new coronavirus disease 2019 (COVID-19): a pictorial review. Eur Radiol 30, 4381-4389 (2020).

4. Wu, F. et al. A new coronavirus associated with human respiratory disease in China. Nature 579, 265-269 (2020).

5. Coperchini, F., Chiovato, L., Croce, L., Magri, F. \& Rotondi, M. The cytokine storm in COVID-19: An overview of the involvement of the chemokine/chemokine-receptor system. Cytokine Growth Factor Rev 53, 25-32 (2020).

6. Ackermann, M. et al. Pulmonary Vascular Endothelialitis, Thrombosis, and Angiogenesis in Covid-19. N Engl J Med 383, 120-128 (2020).

7. Magro, C. et al. Complement associated microvascular injury and thrombosis in the pathogenesis of severe COVID-19 infection: A report of five cases. Transl Res 220, 1-13 (2020).

8. Varga, Z. et al. Endothelial cell infection and endotheliitis in COVID-19. Lancet 395, $1417-1418$ (2020).

9. Bikdeli, B. et al. COVID-19 and Thrombotic or Thromboembolic Disease: Implications for Prevention, Antithrombotic Therapy, and Follow-Up: JACC State-of-the-Art Review. J Am Coll Cardiol 75, 2950-2973 (2020).

10. Levi, M. \& Hunt, B.J. Thrombosis and coagulopathy in COVID-19: An illustrated review. Res Pract Thromb Haemost 4, 744-751 (2020). 
11. Menter, T. et al. Postmortem examination of COVID-19 patients reveals diffuse alveolar damage with severe capillary congestion and variegated findings in lungs and other organs suggesting vascular dysfunction. Histopathology 77, 198-209 (2020).

12. Connors, J.M. \& Levy, J.H. COVID-19 and its implications for thrombosis and anticoagulation. Blood 135, 2033-2040 (2020).

13. Hoffmann, M. et al. SARS-CoV-2 Cell Entry Depends on ACE2 and TMPRSS2 and Is Blocked by a Clinically Proven Protease Inhibitor. Cell 181, 271-280 e278 (2020).

14. Yan, R. et al. Structural basis for the recognition of SARS-CoV-2 by full-length human ACE2. Science 367, 1444-1448 (2020).

15. Shang, J. et al. Structural basis of receptor recognition by SARS-CoV-2. Nature 581, $221-224$ (2020).

16. Hamming, I. et al. Tissue distribution of ACE2 protein, the functional receptor for SARS coronavirus. A first step in understanding SARS pathogenesis. J Pathol 203, 631-637 (2004).

17. Bertram, S. et al. Influenza and SARS-coronavirus activating proteases TMPRSS2 and HAT are expressed at multiple sites in human respiratory and gastrointestinal tracts. PLoS One 7, e35876 (2012).

18. McCray, P.B., Jr. et al. Lethal infection of K18-hACE2 mice infected with severe acute respiratory syndrome coronavirus. J Virol 81, 813-821 (2007).

19. Tseng, C.T. et al. Severe acute respiratory syndrome coronavirus infection of mice transgenic for the human Angiotensin-converting enzyme 2 virus receptor. J Virol 81, 1162-1173 (2007).

20. Netland, J., Meyerholz, D.K., Moore, S., Cassell, M. \& Perlman, S. Severe acute respiratory syndrome coronavirus infection causes neuronal death in the absence of encephalitis in mice transgenic for human ACE2. J Virol 82, 7264-7275 (2008). 
21. Lutz, C., Maher, L., Lee, C. \& Kang, W. COVID-19 preclinical models: human angiotensin-converting enzyme 2 transgenic mice. Hum Genomics 14, 20 (2020).

22. Akkina, R. New generation humanized mice for virus research: comparative aspects and future prospects. Virology 435, 14-28 (2013).

23. Ernst, W. Humanized mice in infectious diseases. Comp Immunol Microbiol Infect Dis 49, 29-38 (2016).

24. Danner, R. et al. Expression of HLA class II molecules in humanized NOD.Rag1KO.IL2RgcKO mice is critical for development and function of human T and B cells. PLoS One 6, e19826 (2011).

25. Majji, S. et al. Differential effect of HLA class-I versus class-II transgenes on human T and B cell reconstitution and function in NRG mice. Sci Rep 6, 28093 (2016).

26. Wijayalath, W. et al. Humanized HLA-DR4.RagKO.IL2RgammacKO.NOD (DRAG) mice sustain the complex vertebrate life cycle of Plasmodium falciparum malaria. Malar J 13, 386 (2014).

27. Kim, J. et al. Tracking Human Immunodeficiency Virus-1 Infection in the Humanized DRAG Mouse Model. Front Immunol 8, 1405 (2017).

28. Majji, S., Wijayalath, W., Shashikumar, S., Brumeanu, T.D. \& Casares, S. Humanized DRAGA mice immunized with Plasmodium falciparum sporozoites and chloroquine elicit protective pre-erythrocytic immunity. Malar J 17, 114 (2018).

29. Jiang, L. et al. Dissemination of Orientia tsutsugamushi, a Causative Agent of Scrub Typhus, and Immunological Responses in the Humanized DRAGA Mouse. Front Immunol 9, 816 (2018).

30. Mendoza, M. et al. Generation and testing anti-influenza human monoclonal antibodies in a new humanized mouse model (DRAGA: HLA-A2. HLA-DR4. Rag1 KO. IL2Rgammac KO. NOD). Hum Vaccin Immunother 14, 345-360 (2018). 
31. Mendoza, M. et al. The humanized DRAGA mouse (HLA-A2. HLA-DR4. RAG1 KO. IL$2 \mathrm{R} \mathrm{g} \mathrm{c} \mathrm{KO.} \mathrm{NOD)} \mathrm{establishes} \mathrm{inducible} \mathrm{and} \mathrm{transmissible} \mathrm{models} \mathrm{for} \mathrm{influenza} \mathrm{type} \mathrm{A}$ infections. Hum Vaccin Immunother, 16, 1-16 (2020).

32. Zhou, B. et al. The pathological autopsy of coronavirus disease 2019 (COVID-2019) in China: a review. Pathog Dis 78 (2020).

33. Bradley, B.T. et al. Histopathology and ultrastructural findings of fatal COVID-19 infections in Washington State: a case series. Lancet (2020).

34. Sauter, J.L. et al. Insights into pathogenesis of fatal COVID-19 pneumonia from histopathology with immunohistochemical and viral RNA studies. Histopathology (2020).

35. Piet, B. et al. CD8(+) T cells with an intraepithelial phenotype upregulate cytotoxic function upon influenza infection in human lung. J Clin Invest 121, 2254-2263 (2011).

36. Purwar, R. et al. Resident memory $T$ cells $(T(R M))$ are abundant in human lung: diversity, function, and antigen specificity. PLoS One 6, e16245 (2011).

37. Zou, X. et al. Single-cell RNA-seq data analysis on the receptor ACE2 expression reveals the potential risk of different human organs vulnerable to 2019-nCoV infection. Front Med 14, 185-192 (2020).

38. Xu, Z. et al. Pathological findings of COVID-19 associated with acute respiratory distress syndrome. Lancet Respir Med 8, 420-422 (2020).

39. Chai, X. et al. Specific ACE2 expression in cholangiocytes may cause liver damage after 2019-nCoV infection. BioRxiv https://doi.org/10.1101/2020.02.03.931766 (2020).

40. Xiao, F. et al. Evidence for Gastrointestinal Infection of SARS-CoV-2. Gastroenterology 158, $1831-1833$ e1833 (2020).

41. Chu, K.H. et al. Acute renal impairment in coronavirus-associated severe acute respiratory syndrome. Kidney Int 67, 698-705 (2005).

42. Helms, J. et al. Neurologic Features in Severe SARS-CoV-2 Infection. N Engl J Med 382, 2268-2270 (2020). 
43. Chen, L., Li, X., Chen, M., Feng, Y. \& Xiong, C. The ACE2 expression in human heart indicates new potential mechanism of heart injury among patients infected with SARSCoV-2. Cardiovasc Res 116, 1097-1100 (2020).

44. Liu, K. et al. SARS-CoV-2 effects in the genitourinary system and prospects of sex hormone therapy. Asian J Urol (2020).

45. Le Bert, N. et al. SARS-CoV-2-specific T cell immunity in cases of COVID-19 and SARS, and uninfected controls. Nature (2020).

46. de Bree, G.J. et al. Selective accumulation of differentiated CD8+ T cells specific for respiratory viruses in the human lung. J Exp Med 202, 1433-1442 (2005).

47. Pichyangkul, S. et al. Tissue Distribution of Memory T and B Cells in Rhesus Monkeys following Influenza A Infection. J Immunol 195, 4378-4386 (2015).

48. Slutter, B., Pewe, L.L., Kaech, S.M. \& Harty, J.T. Lung airway-surveilling CXCR3(hi) memory CD8(+) T cells are critical for protection against influenza A virus. Immunity 39, 939-948 (2013).

49. Turner, D.L. et al. Lung niches for the generation and maintenance of tissue-resident memory T cells. Mucosal Immunol 7, 501-510 (2014).

50. Wu, T. et al. Lung-resident memory CD8 T cells (TRM) are indispensable for optimal cross-protection against pulmonary virus infection. J Leukoc Biol 95, 215-224 (2014).

51. Park, S.L. et al. Local proliferation maintains a stable pool of tissue-resident memory $\mathrm{T}$ cells after antiviral recall responses. Nat Immunol 19, 183-191 (2018).

52. Hassan, A.O. et al. A SARS-CoV-2 Infection Model in Mice Demonstrates Protection by Neutralizing Antibodies. Cell 182, 744-753 e744 (2020).

53. Cohen, J. Antibodies may curb pandemic before vaccines. Science 369, 752-753 (2020).

54. Zost, S.J. et al. Potently neutralizing and protective human antibodies against SARSCoV-2. Nature (2020). 
55. Sekine, T. et al. Robust T Cell Immunity in Convalescent Individuals with Asymptomatic or Mild COVID-19. Cell 183, 158-168 e114 (2020).

56. Mentzer, S.J. \& Konerding, M.A. Intussusceptive angiogenesis: expansion and remodeling of microvascular networks. Angiogenesis 17, 499-509 (2014).

57. Ojo, A.S., Balogun, S.A., Williams, O.T. \& Ojo, O.S. Pulmonary Fibrosis in COVID-19 Survivors: Predictive Factors and Risk Reduction Strategies. Pulm Med 2020, 6175964 (2020).

58. Phillips, R.J. et al. Circulating fibrocytes traffic to the lungs in response to CXCL12 and mediate fibrosis. J Clin Invest 114, 438-446 (2004).

59. Venkataraman, T., Coleman, C.M. \& Frieman, M.B. Overactive Epidermal Growth Factor Receptor Signaling Leads to Increased Fibrosis after Severe Acute Respiratory Syndrome Coronavirus Infection. J Virol 91 (2017). 


\section{ONLINE METHODS}

HIS-reconstitution of DRAGA mice. DRAGA mice express the HLA-A2.1 and HLA-DR0401 transgenes on a Rag1KO.IL2RycKO.NOD (NRG) background, and they have been described previously ${ }^{28-31}$ HLA-A2.1.HLA-DR0401 positive umbilical cord blood was obtained from the New York Blood Center (Long Island City, NY, USA). Mice were irradiated (350 rads) and injected intravenously with $\mathrm{CD}^{+} \mathrm{T}$-cell-depleted cord blood cells (EasySep Human CD3 Positive Selection Kit, Stem Cell Technologies, Vancouver, BC, Canada) containing approximately $10^{5}$ human $\mathrm{CD}_{3}{ }^{+}$hematopoietic stem cells (HSC) determined by FACS using a mouse anti-human CD34 antibody (BD Biosciences, San Jose, CA, USA) as described ${ }^{49,52,54}$. The procedures for assessing human T and B cell reconstitution in peripheral blood by FACS have been described ${ }^{49,52,54}$. As documented in our previous studies, $>90 \%$ of HIS-reconstituted DRAGA mice generated using these procedures reconstitute a human immune system by 3 to 4 months post-CD $34^{+}$HSC infusion. The human reconstitution status of DRAGA mice at the time of our SARS-CoV-2 infection experiments was determined based on FACS measurement of T cells and B cells in peripheral blood (Table S1).

RT-PCR detection of hACE2 mRNA in HIS-DRAGA mouse lungs. RNA was extracted using a Qiagen RNA extraction kit (Qiagen, Hilden, Germany) from lungs of HIS-DRAGA and control (non-HSC-infused DRAGA) mice. Human lung mRNA (Sigma-Aldrich, St. Louis, MO, USA) served as a positive control. PCR primers specific for hACE2 were: forward, CAGGAAATGTTCAGAAAGCA and reverse, TCTTAGCAGAAAAGGTTGTG. The murine ACE2 specific primers were: forward: AGCAGATGGCCGGAAAGTTG, and reverse:

TCTTAGCAGGAAAGGTTGCC. RT-PCR was performed using a One-step RT-PCR kit (Qiagen) for 45 cycles using $1 \mu \mathrm{g}$ RNA template and $1.6 \mu \mathrm{M}$ of each primer, following the 
manufacturer's instructions. The PCR amplicons were run on a $3 \%$ agarose gel. PCR bands were purified from the agarose gels and nucleotide sequenced (Eurofins, Coralville, lowa, USA).

\section{RT-qPCR measurement of viral RNA copies in SARS-CoV-2 infected HIS-DRAGA mouse}

lungs. RNA from lungs of mice \#M2-M4 and \#F11-F13 was extracted using RNA-STAT 60 extraction reagent (Tel-Test, Inc., Friendswood, TX, USA) + chloroform, precipitated and resuspended in RNAse-free water. Control RNA was isolated from SARS-CoV-2 viral stocks following the same procedure and quantified by OD260. These control stocks were serially diluted and OD260 values measured to generate a standard curve. RT-qPCR of the lung RNA was carried out using the following primers : 2019-nCoV_N1-F :5'-GAC CCC AAA ATC AGC GAA AT-3'; 2019-nCoV_N1-R: 5'-TCT GGT TAC TGC CAG TTG AAT CTG-3'; and probe 2019-nCoV_N1-P: 5'-FAM-ACC CCG CAT TAC GTT TGG TGG ACC-BHQ1-3' (Integrated DNA Technologies, Coralville, IA, USA) which were designed to bind to and amplify a conserved region of SARS-CoV-2 Nucleocapsid (N) RNA. Amplification was performed with an Applied Biosystems 7500 Sequence detector using the following program: $48^{\circ} \mathrm{C}$ for 30 minutes, $95^{\circ} \mathrm{C}$ for 10 minutes followed by 40 cycles of $95^{\circ} \mathrm{C}$ for 15 seconds, and 1 minute at $55^{\circ} \mathrm{C}$. Reactions were carried out using a TaqMan RT-PCR kit (Meridian Bioscience, Memphis, TN, USA) in 50 $\mu \mathrm{L}$ volume containing $5 \mu \mathrm{L}$ of template, $2 \mu \mathrm{M}$ of each primer and $2 \mu \mathrm{M}$ of each probe. The number of viral RNA copies per $\mathrm{mL}$ was calculated by extrapolation from the standard curve, and values were then converted to the number of viral RNA copies per gram of lung tissue.

\section{Extraction and quantification of hACE2 protein in HIS-DRAGA and non-HIS-reconstituted}

DRAGA mouse lungs and in a human lung control. Lungs from 10 non-infected HIS-DRAGA and 10 non-infected, non-HIS reconstituted DRAGA mice were homogenized in the presence of MPER mammalian protein extraction reagent (Fisher Scientific, Waltham, MA, USA) containing complete protease inhibitor cocktail tablets (Roche Diagnostics $\mathrm{GmbH}$, Mannheim, Germany) 
using tubes loaded with ceramic beads (MP Biologicals, Irvine, CA, USA) in a Fast-prep homogenizer (MP Biologicals). Pooled lung homogenates from each group of mice were sonicated on ice in a Fisher Ultrasonicator for 10 cycles of 10 seconds each, the cellular debris was removed by centrifugation at 5,000 rpm, and the protein in the clear supernatant was quantified using a BCA reagent (Thermo Fisher Scientific, Waltham, MA, USA). 9 mg of total lung protein extract from each group of mice and $2 \mathrm{mg}$ of human lung total protein lysate (Zyagen, San Diego, CA, USA) were then individually incubated with gentle shaking (300 strokes per min) in an Eppendorf thermomixer for $1 \mathrm{~h}$ at $37^{\circ} \mathrm{C}$ with $10 \mu \mathrm{g}$ of the $\mathrm{S} 1$ (RBD)mFcy2a protein (ACRO Biosystems, Newark, DE, USA) followed by incubation with gentle shaking for $1 \mathrm{~h}$ at $37^{\circ} \mathrm{C}$ with $50 \mu \mathrm{l}$ of rat anti-mouse IgG2a-magnetic microbeads (Miltenyi Biotech, Berdisch Gladback, Germany). The total lysate from each sample was next passed

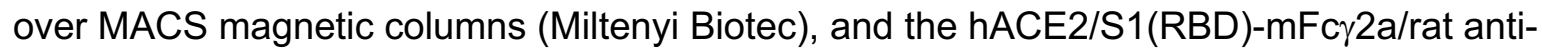
mouse IgG2a-magnetic beads were eluted according to the manufacturer's instructions and concentrated to $52 \mu$ each. The amounts of hACE2 protein in these immunoprecipitates were then quantified using the highly sensitive human ACE2 ELISA kit PicoKine ${ }^{\mathrm{TM}}$ (Boster Biological Technology, Pleasanton, CA) per the manufacturer's protocol. The provided recombinant hACE2 protein was serially diluted in the provided sample buffer. The human lung sample was diluted 1:100 and the DRAGA and HIS-DRAGA samples were diluted 1:50 each in the provided sample buffer. OD450nm values were then read for duplicate samples (100 $\mu$ l each) using a BioTEK microplate reader (BioTek Instruments, Inc., Winooski, VT, USA). A hACE2 standard curve was constructed by applying a four-parameter logistic fit formula using the BioTEK Gen 5 software (BioTek Instruments, Inc.). The sample OD450nm mean values were then converted to hACE2 concentrations using this curve, per the manufacturer's instructions.

\section{Western blot analysis of hACE2 protein in HIS-DRAGA lung lysates.}


Western blots were next run using aliquots from the same concentrated immunoprecipitates used for the ELISA assays above: immunoprecipitates obtained from (1) 2 mg human lung extract; (2) 9 mg HIS-DRAGA mice lungs lysate; (3) 9 mg DRAGA mice lungs lysate. One $\mu$ l of each immunoprecipitate added to wells of a $4-12 \%$ Bis-Tris gradient pre-cast gel from Invitrogen (Thermo Fisher Scientific, Waltham, MA, USA) and the samples were electrophoresed under denaturing conditions and then electro-transferred onto a PVDF membrane. The membrane was blocked overnight at $4^{\circ} \mathrm{C}$ with shaking using $5 \%$ non-fat milk plus $3 \%$ BSA in PBS, incubated with a mouse monoclonal anti-human ACE2 (Abcam, Cambridge, MA, USA, 1:750) for $2 \mathrm{~h}$ at room temperature, and washed with PBS $+0.01 \%$ Tween 20 . The membrane was then incubated with goat anti-mouse IgG-HRP (Santa Cruz Biotechnology, Dallas, TX, USA, 1:3000) and SuperSignal ${ }^{\mathrm{TM}}$ West Pico PLUS chemiluminescent substrate according to the manufacturer's instructions (Thermo Fisher Scientific). The chemiluminescent bands were then imaged using a Fluorchem E Imaging System (ProteinSimple, San Jose, CA, USA).

Infection of mice with SARS CoV-2 virus. HIS-DRAGA mice were infected intranasally (i.n.) with SARS CoV-2 strain USA-WA1/2020 (BEI Resources NR-52281, batch \#70033175), courtesy of the Centers for Diseases Control and Prevention (CDC). This virus strain was originally isolated from an oropharyngeal swab of a patient with a respiratory illness who had returned to Washington State, USA, from travel to China and developed COVID-19 in January 2020. Infection of HIS-DRAGA mice and harvesting of serum and organs were conducted in a BSL-3 laboratory at Bioqual, Inc. (Rockville, MD, USA) in compliance with local, state, and federal regulations under IACUC protocol \#20-019P. The SARS-COV-2 stock was expanded in Vero E6 cells, and the challenging virus was collected at day 5 of culture when the infection reached $90 \%$ cytopathic effect. The full viral genome sequence showed $100 \%$ identity with the parent virus sequence listed in GenBank (MN985325.1). A plaque forming assay carried out with confluent layers of Vero E6 cells was used to determine the concentration of live virions, 
reported as plaque-forming units (pfu). HIS-DRAGA mice were infected i.n. with three different doses $\left(2.8 \times 10^{3}\right.$, or $2.8 \times 10^{4}$, or $\left.1 \times 10^{3} \mathrm{pfu}\right)$ of the same SARS-COV-2 virus strain (NR-52281, batch \#70033175) as summarized in Table S1.

Measurement of antibody serum titers to SARS-CoV-2 viral proteins. Titers of human IgM and IgG serum antibodies (1/20 serum dilution) to the recombinant $S 1(R B D)$ viral protein from mice infected i.n. with SARS-CoV-2 virions $\left(10^{3} \mathrm{pfu} /\right.$ mouse $)$ were measured prior to infection and at 24 dpi using ELISA kits according to the manufacturer's instructions (Bethyl Laboratories). In addition, titers of human IgM and IgG serum antibodies in aliquots of these same serum samples against a recombinant His-tagged $S$ trimeric protein and against a recombinant His-tagged $\mathrm{N}$ protein (both from ACRO Biosystems) were determined using an inhouse ELISA. Briefly, His-S trimeric protein or His-N protein, respectively, were coated on highbinding ELISA plates (Corning Costar, Fisher Scientific, Waltham, MA, USA) at 0.2 $\mu \mathrm{g} / \mathrm{well} / 100 \mu \mathrm{L}$ in carbonate buffer, $\mathrm{pH} 9.0$. The plates were then incubated overnight at $4^{\circ} \mathrm{C}$, then blocked with PBS $+1 \%$ BSA for $2 \mathrm{~h}$ at room temperature, washed with PBS $+0.05 \%$ Tween 20, and incubated at room temperature for $1 \mathrm{~h}$ with the serum samples diluted in PBS + $1 \%$ BSA $+0.05 \%$ Tween 20 . Bound human $\lg M$ and $\lg$ antibodies against the His-S trimer protein were then revealed by adding anti-human IgM or IgG antibody-HRP conjugates (Bethyl Laboratories) to the His-S-trimer-coated plates. Due to limited serum volumes, total IgG + IgM antibodies against the His- $\mathrm{N}$ protein were revealed by adding anti-human kappa plus lambda antibody-HRP conjugates (Bethyl Laboratories) to the His-N protein coated plates. The ELISA plates were then incubated with soluble HRP substrate for 15 minutes, and reactions were stopped by adding $\mathrm{H}_{2} \mathrm{SO}_{4}(0.18 \mathrm{M}, 100 \mu \mathrm{L} /$ well). Plates were read in an ELISA reader at 450nm and $570 \mathrm{~nm}$. OD450nm values were corrected by subtracting the OD570nm values (ranging from $0.045-0.067$ ) of serum samples from the same mice prior to infection. Standard deviations 
(+/-SD) for each serum sample in duplicate wells were determined at $99 \%$ interval of confidence by SigmaPlot v.14 software. The positive control (anti-S1(RBD)) antibody from the kit was used as a positive control for both S1(RBD) and S1-trimer binding ELISA assays. The antibody titer against the $\mathrm{N}$ protein in serum from a non-infected mouse served as a negative control for the N-binding ELISA assays.

Histopathology of lungs from infected HIS-DRAGA mice. Lungs harvested from infected mice at the experimental end-points (14 dpi or $25 \mathrm{dpi}$ ) were fixed in 10\% formalin, embedded in a paraffin block, and $5 \mu \mathrm{m}$ sections were stained with Hematoxylin/Eosin (H\&E) or Masson's Trichrome by Histoserv, Inc. (Germantown, MD, USA). Microscopic images were captured using an Olympus BX43 microscope (Shinjuku-ku, Tokyo, Japan).

Immunofluorescence microscopy. Tissue sections $(5 \mu \mathrm{m})$ from paraffin-embedded cassettes or frozen OCT cassettes from infected and non-infected HIS-DRAGA mice, and from noninfected, non-HIS reconstituted DRAGA mice were prepared by Histoserv, Inc. Thawed OCTfrozen tissue slides were rehydrated with PBS, and paraffin-embedded sections were deparaffinized with xylene and rehydrated with graded concentrations of ethanol. Slides were then fixed, permeabilized with fixation/permeabilization buffer (Invitrogen, Waltham, MA, USA), blocked with $3 \% \mathrm{BSA}$ in PBS for $30 \mathrm{~min}$ at $37^{\circ} \mathrm{C}$, and stained with fluorochrome-conjugated antibodies in PBS containing $0.01 \%$ Evans Blue at $37^{\circ} \mathrm{C}$ for $50 \mathrm{~min}$. To visualize hACE2, slides were probed with the S1(RBD)-mFcy2a protein $(10 \mu \mathrm{g} / \mathrm{ml})$, washed with PBS, and then incubated with a goat anti-mouse IgG-FITC conjugate (Southern Biotech, Birmingham, AL, USA). Other antibodies to detect antigens of interest were: anti-human CD3-FITC, anti-human CD4-PE, anti-human CD8-PE, anti-human CD45-FITC, anti-human granzyme-B-PE, antihuman CD103-FITC (all from BD Biosciences, San Jose, CA, USA), anti-human CD326-PE (Miltenyi Biotech), anti-human Perforin-PE (Biolegend, San Diego, CA, USA), anti-human 
CD103-FITC (BD PharMingen, Irvine, CA, USA), anti-mouse CD61-PE (Invitrogen), and antihACE2 antibody (clone\# MM0073—11A3, Abcam), anti-human TMPRSS2 monoclonal IgG1 mouse antibody (\#clone P5H9-A3, Sigma Aldrich), mouse IgG1/K-Alexa Fluor 594 anti-human CD31 Antibody (clone WM59, Biolegend), goat F(ab')2 anti-mouse IgG1-PE conjugate (Southern Biotech), and goat F(ab')2 IgG anti-mouse IgG2a (Southern Biotech). After staining, the slides were washed $3 \mathrm{X}$ with PBS, air-dried, and mounted with $10 \mu$ of Vectashield containing DAPI (Vector Laboratories, Burlingame, CA, USA), and images were acquired with a Zeiss Axioscan Confocal microscope or an Olympus BX43 microscope. 


\section{FIGURES}
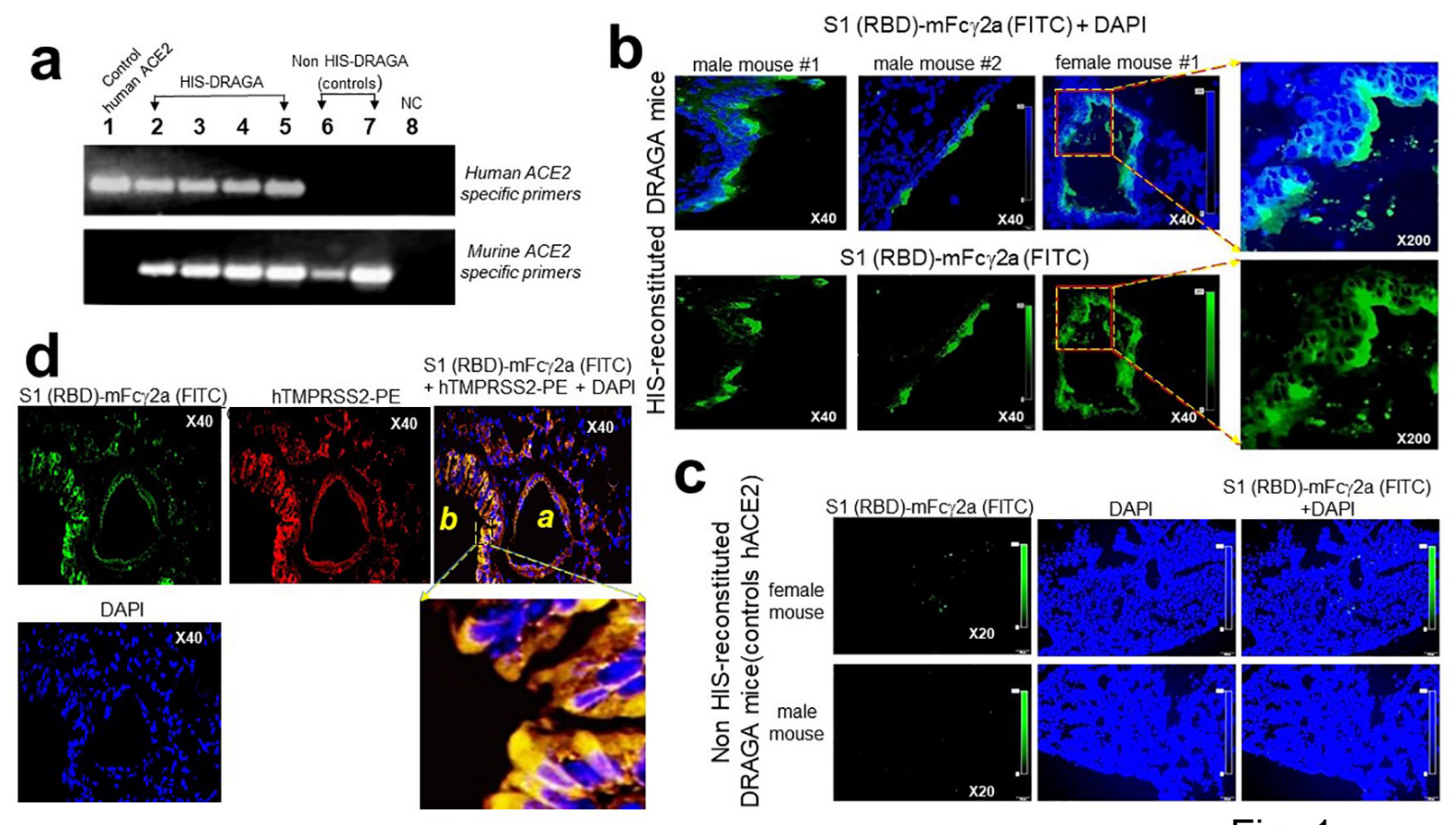

Fig. 1

Figure 1. Human ACE2 and TMPRSS2 detection in the lungs of non-infected HIS-DRAGA and DRAGA mice. a. Positive control $(+)=$ human lung mRNA. Negative control $(-)=$ primers alone. upper row, PCR amplicons of $h A C E 2$ from the lungs of 4 HIS-DRAGA mice (2 females and 2 males) and 2 non-HIS-reconstituted DRAGA mice (1 female and 1 male), amplified using hACE2-specific primers. Lower row, PCR amplicons of the same lung samples in the upper row, amplified using mACE2specific primers. b. hACE2 protein expression on alveolar epithelia as indicated by binding of the S1(RBD)-mFc 2a protein + goat anti-mouse IgG-FITC in lung sections from a representative HISDRAGA female mouse and two HIS-DRAGA male mice. Upper panels, merged images of S1(RBD)$\mathrm{mFc} 2 \mathrm{a}$ binding (green) and nuclei (blue, DAPI), and an enlargement of the hACE2 ${ }^{+}$alveolar epithelia. Lower panels, binding of S1(RBD)-mFc 2a protein + goat anti-mouse IgG-FITC and an enlargement of the hACE2 ${ }^{+}$alveolar epithelia. c. Same staining protocol as in a for lung sections from two non-HIS reconstituted DRAGA mice showing very weak binding (female mouse) and no detectable binding (male mouse) of S1(RBD)-mFc 2a protein, indicating siginificantly weaker avidity of the $S 1$ viral protein for the murine than the human ACE2 receptor. d. lung section from a representative HIS-DRAGA female mouse showing hTMPRSS2 co-localization with hACE2 as revealed by S1(RBD)-mFc 2a protein + goat anti-mouse IgG-FITC (green) and anti-human TMPRSS2-PE (red) on the epithelial wall of a bronchiole $(b)$ and the endothelial wall of a pulmonary arteriole (a). A section of the bronchiole image is also shown enlarged 200X. 

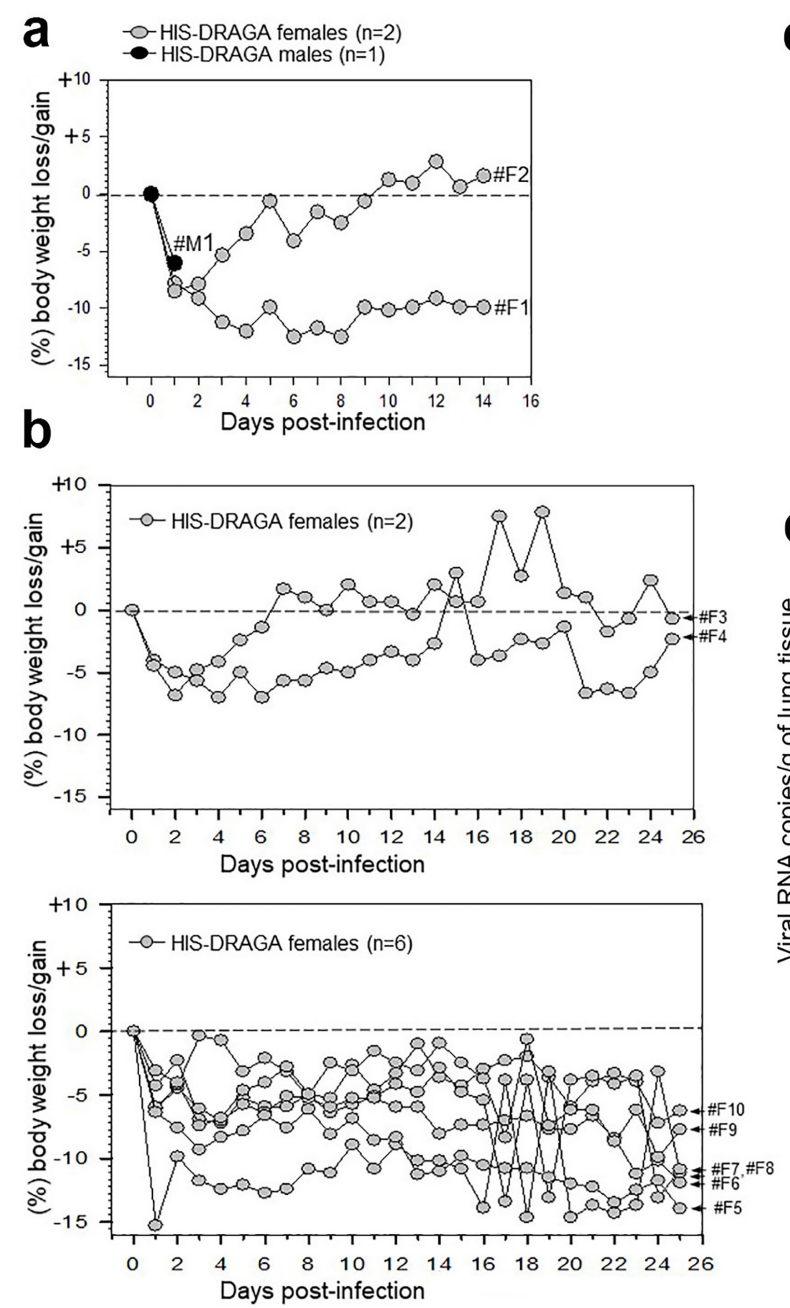

Figure 2. Post-infection body weights and viral titers. a. Changes in \% body weights of HISDRAGA mice \#M1 infected with SARS-CoV-2 virions (2.8x10 pfu) and \#F1 and \#F2 infected with $2.8 \times 10^{4}$ pfu and $2.8 \times 10^{3}$ pfu, respectively ( $1^{\text {st }}$ infection experiment). b. Changes in $\%$ body weights for 8 HIS-DRAGA mice infected with $10^{3}$ pfu of SARS CoV-2 virions ( $2^{\text {nd }}$ infection experiment). Shown are the mice that recovered their initial body weights after infection (upper panel), and those that did not (lower panel). c. Changes in \% body weights for 6 HIS-DRAGA mice infected with $10^{3}$ pfu SARSCoV-2 virions ( $3^{\text {rd }}$ infection experiment). d. SARS-CoV-2 viral loads in the lungs of 6 infected HISDRAGA mice $\left(10^{3} \mathrm{pfu} /\right.$ mouse $)$ as quantified by RT-qPCR ( $3^{\text {rd }}$ infection experiment) at $4 \mathrm{dpi}$. There was no significant difference between the viral RNA copies in lungs of female versus male mice. 

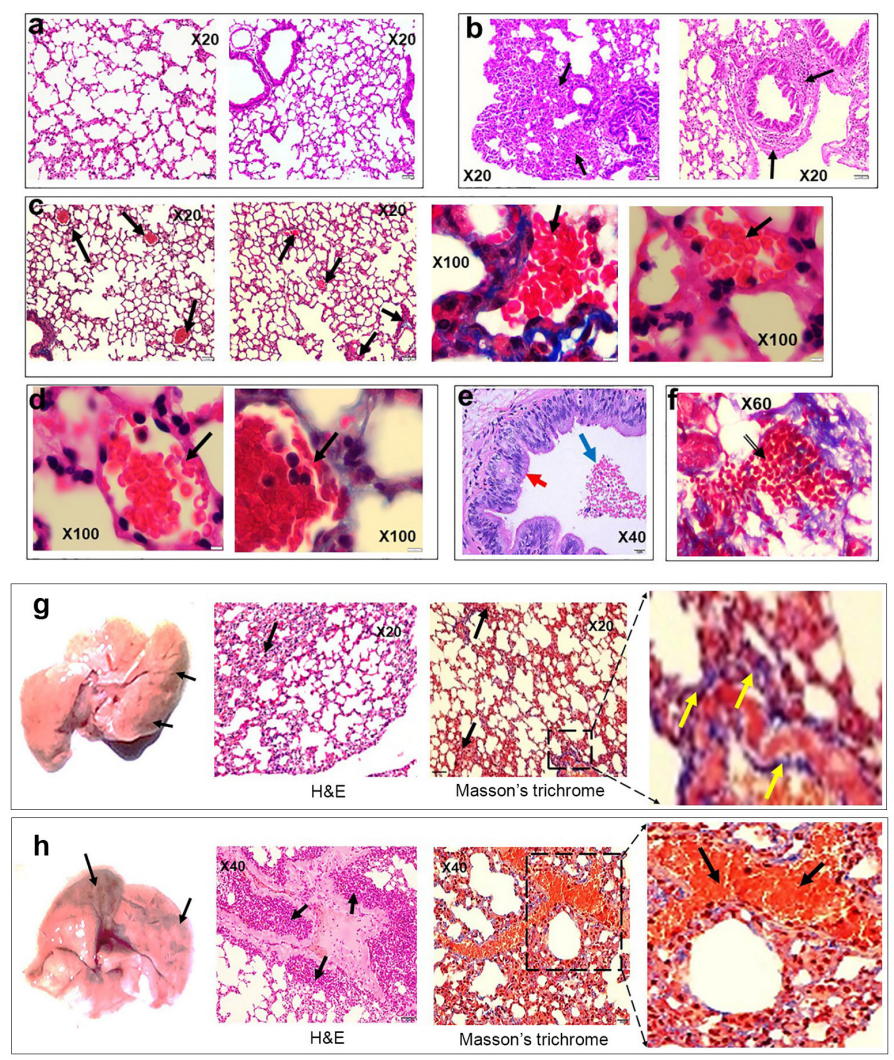

Fig. 3

Figure 3. Lung pathology of HIS-DRAGA mice infected with SARS-CoV-2. a. H\&E-stained lung sections from two non-infected HIS-DRAGA mice showing healthy alveolar architecture and two bronchioles lacking lymphocytic infiltration. b. Two separate H\&E-stained sections of the lungs from HISDRAGA mouse \#F1 infected with $2.8 \times 10^{4}$ pfu, which did not recover its initial body weight at the experimental endpoint (14 dpi). Heavily infiltrated areas at the lung periphery and surrounding a bronchiole are shown (arrows), and distorted alveolar architecture was also observed. c. Masson's Trichrome-stained sections of a lung from mouse \#F1 showing multiple intra-arteriolar microthrombi (left panel, arrows) and intra-alveolar microthrombi (3 right panels, arrows). d. Masson's Trichrome-stained sections of a lung from mouse \#F1 showing adherence of red blood cells to the endovasculature (arrows). e. H\&E staining of a representative lung section from mouse \#F1 showing a large intrabronchiolar blood clot (blue arrow). Also shown are the bronchus columnar ciliated cells of epithelia (red arrow). f. Representative Masson's Trichrome-stained section of a lung from mouse \#F1 showing a large interstitial hemorrhagic area (arrow). g. Morphologic image of the lungs (left panel) and H\&E and Masson's Trichrome-stained sections of the lungs (right panels) from the HIS-DRAGA mouse \#F3 infected with $10^{3} \mathrm{pfu}$, which recovered its initial body weight at $7 \mathrm{dpi}$. Discoloration on the left lobe (arrows) and a few, small interstitial and peripheral infiltrates are indicated by arrows. Enlargement shows incipient peri-alveolar collagen deposition as a sign of developing pulmonary sequelae. $\mathbf{h}$. Morphologic image of the lungs (left panel) and the H\&E and Masson's Trichrome-stained sections of the lungs (right panels) from HIS-DRAGA mouse \#F5 infected with $10^{3}$ pfu of SARS-CoV-2, which sustained the infection but did not recover its initial body weight by $25 \mathrm{dpi}$. Shown is a large discolored area of the upper right lobe (arrow), heavy infiltration with disrupted alveolar architecture (arrows, middle panel), and a large hemorrhagic patch in vicinity of a major bronchiole (arrows, right panel and enlargement). 

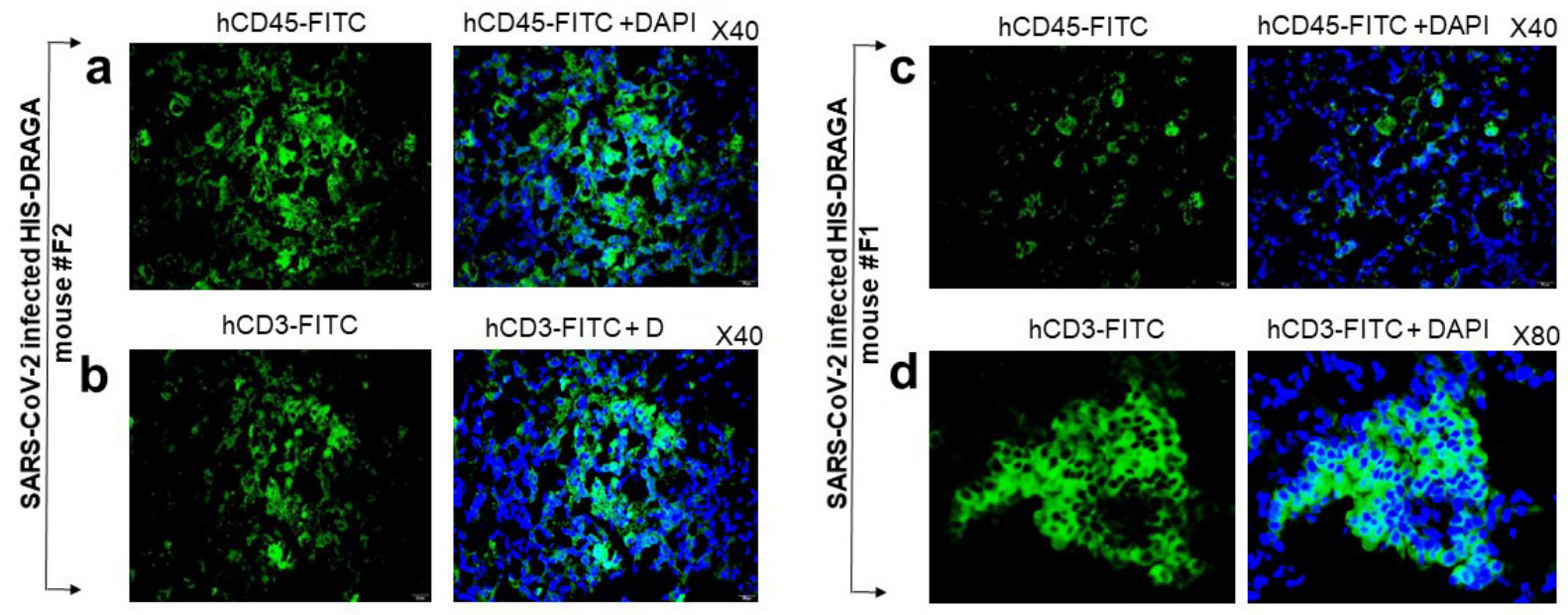

Fig. 4

Figure 4. Infiltrating human lymphocytes in the lungs of SARS-CoV-2 infected HIS-DRAGA mice. Lung sections from HIS-DRAGA mice \#F2 and \#F1 infected with $2.8 \times 10^{3}$ pfu and $2.8 \times 10^{4}$ pfu, respectively, stained with anti-hCD45-FITC or anti-hCD3FITC at the experimental endpoint (14 dpi). a,b. hCD $45^{+}$and $\mathrm{hCD}^{+}$cell infiltrates in the lungs of \#F2 mouse recovering from infection. c,d. hCD45 $5^{+}$and $\mathrm{hCD}^{+}$cell infiltrates in the lungs of mouse \#F1, which did not recover from infection. Of note, infiltrating $\mathrm{CD}^{+} \mathrm{T}$ cells were clustered in lung epithelial niches of mouse \#F2 whereas $\mathrm{CD}^{+} \mathrm{T}$ cell infiltrates in mouse \#F1 were more dispersed. 


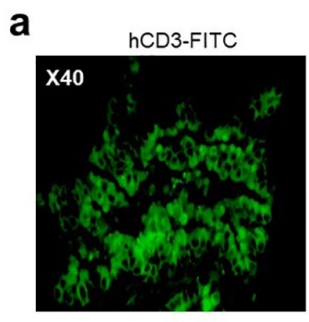

b

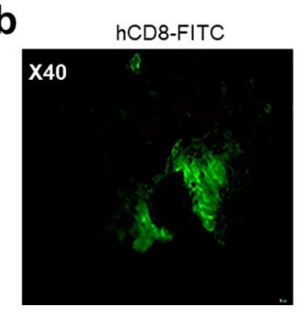

C

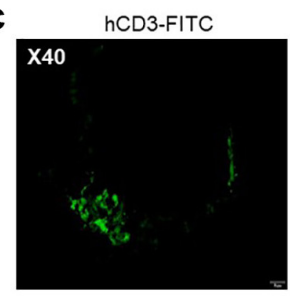

d

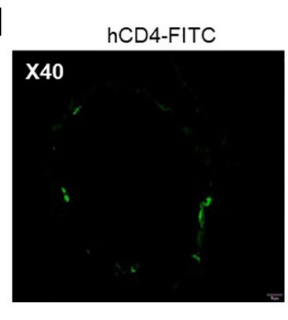

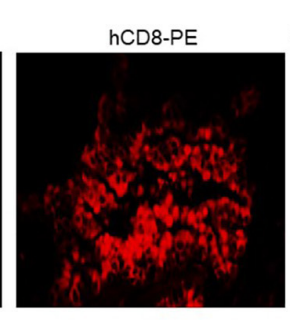

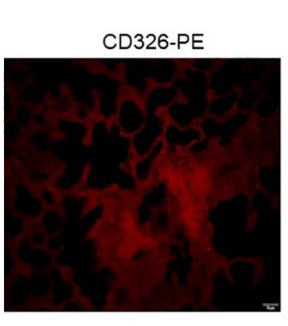

hCD8-FITC + CD326-PE

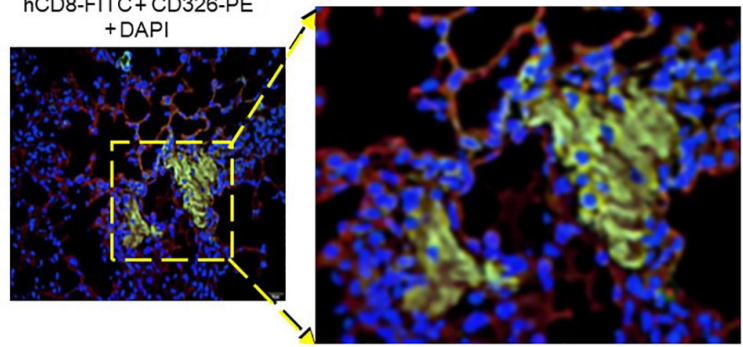

hCD4-PE
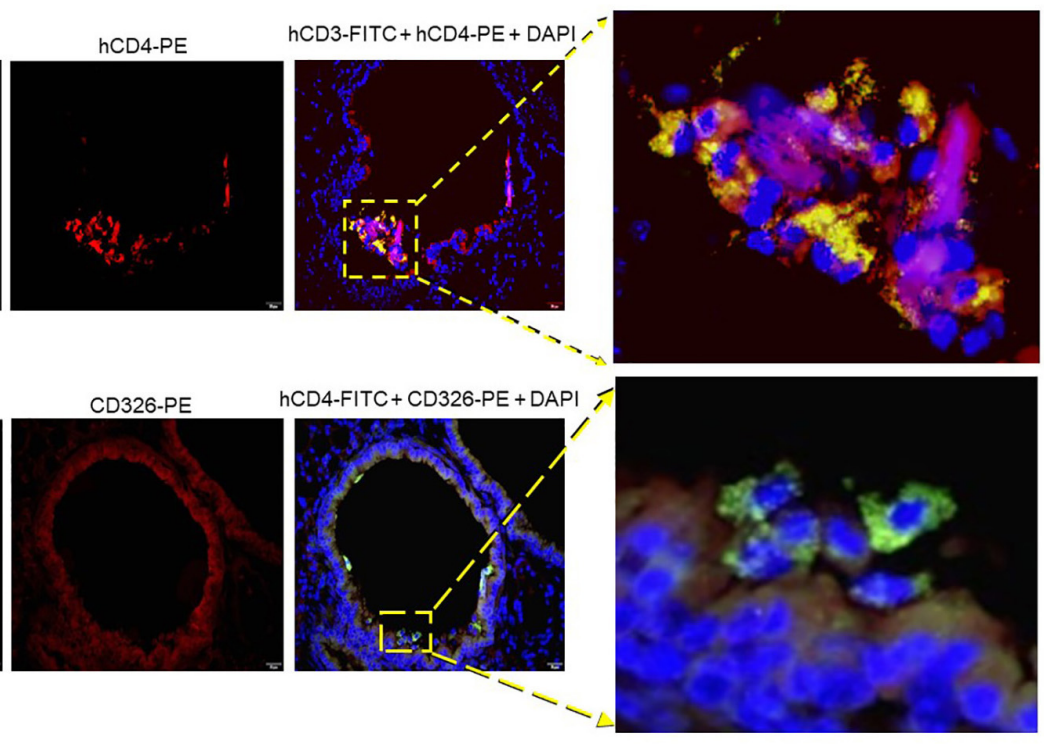

Fig. 5

Figure 5. Human $\mathrm{CD8}^{+}$and $\mathrm{CD4}^{+} \mathrm{T}$ cells in $\mathrm{CD}^{2} \mathrm{6}^{+}$lung niches in SARS-CoV-2 infected HISDRAGA mice. a. Representative lung section from HIS-DRAGA mouse \#F2 infected with $2.8 \times 10^{3}$ pfu that recovered its initial body weight at $14 \mathrm{dpi}$, co-stained with anti-hCD3-FITC and anti-hCD8-PE antibodies. Enlargement shows an area with a large cluster of $\mathrm{hCD} 3^{+} \mathrm{CD} 8^{+} \mathrm{T}$ cells (orange) sequestered in the lung epithelia, with some $\mathrm{hCD} 3^{+} \mathrm{CD} 8^{+} \mathrm{T}$ cells egressing into the alveolar air space. $\mathbf{b}$. Lung section from the same infected mouse (\#F2) co-stained for hCD8 and hCD326 (epithelial marker). Enlargement shows a large cluster of hCD8 ${ }^{+} \mathrm{T}$ cells co-localized with the $\mathrm{hCD} 326^{+}$lung epithelia. c. Lung section from HIS-DRAGA mouse \#F2 infected with $2.8 \times 10^{3}$ pfu that recovered its initial body weight at $9 \mathrm{dpi}$, co-stained with anti-hCD3-FITC and anti-hCD4-PE antibodies. Enlargement shows a few $\mathrm{hCD}^{+} \mathrm{CD} 4^{+}$ $\mathrm{T}$ cells (yellow). d. lung section from the same mouse (\#F2) showing hCD4 ${ }^{+} \mathrm{T}$ cells co-localized with the $\mathrm{CD}_{2} 26^{+}$epithelial layer. Enlargement shows an area containing co-localized CD326 ${ }^{+}$lung ECs with $\mathrm{CD}^{+} \mathrm{T}$ cells egressing into the alveolar air space (orange). 

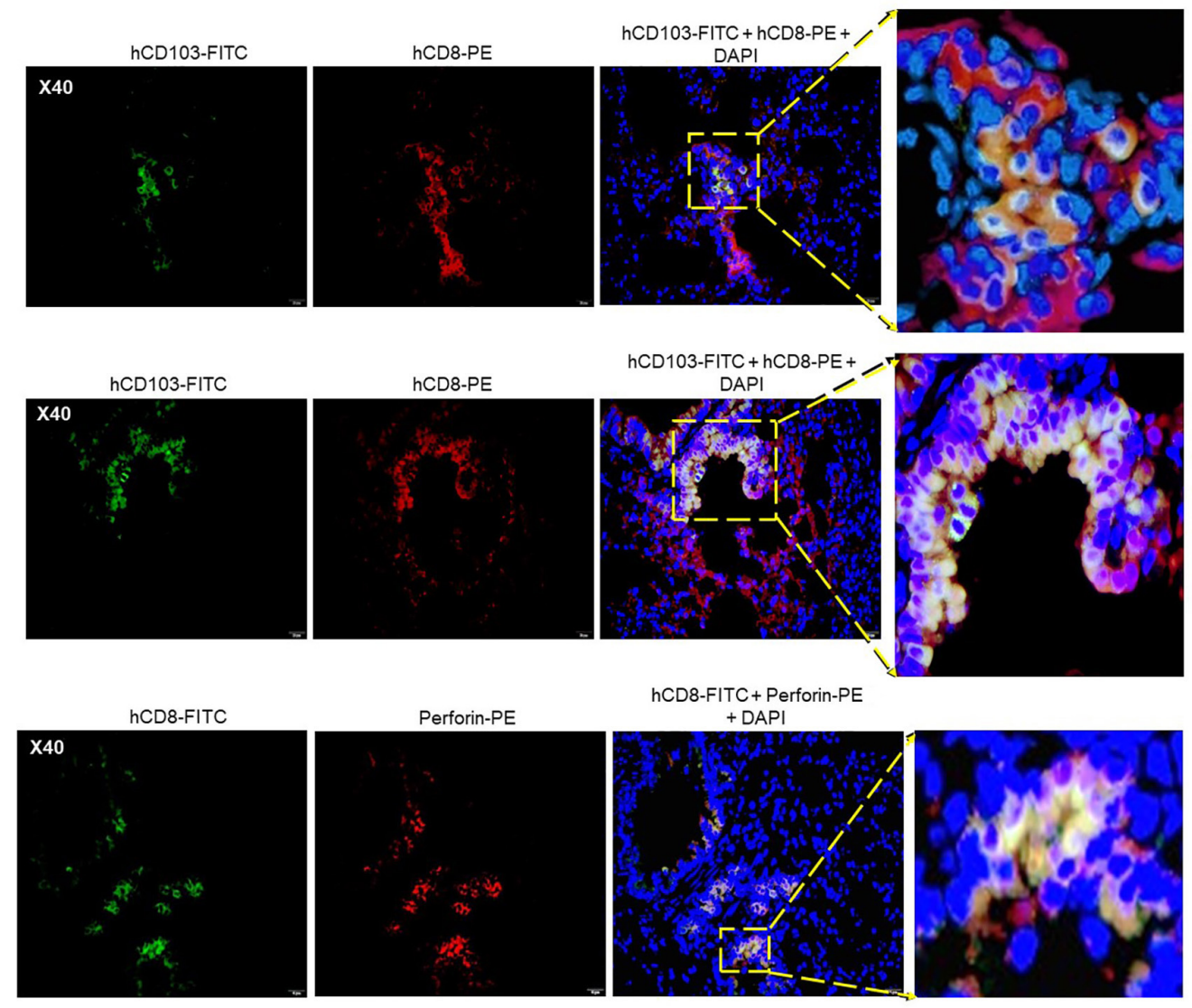

hCD8-FITC+ Perforin-PE
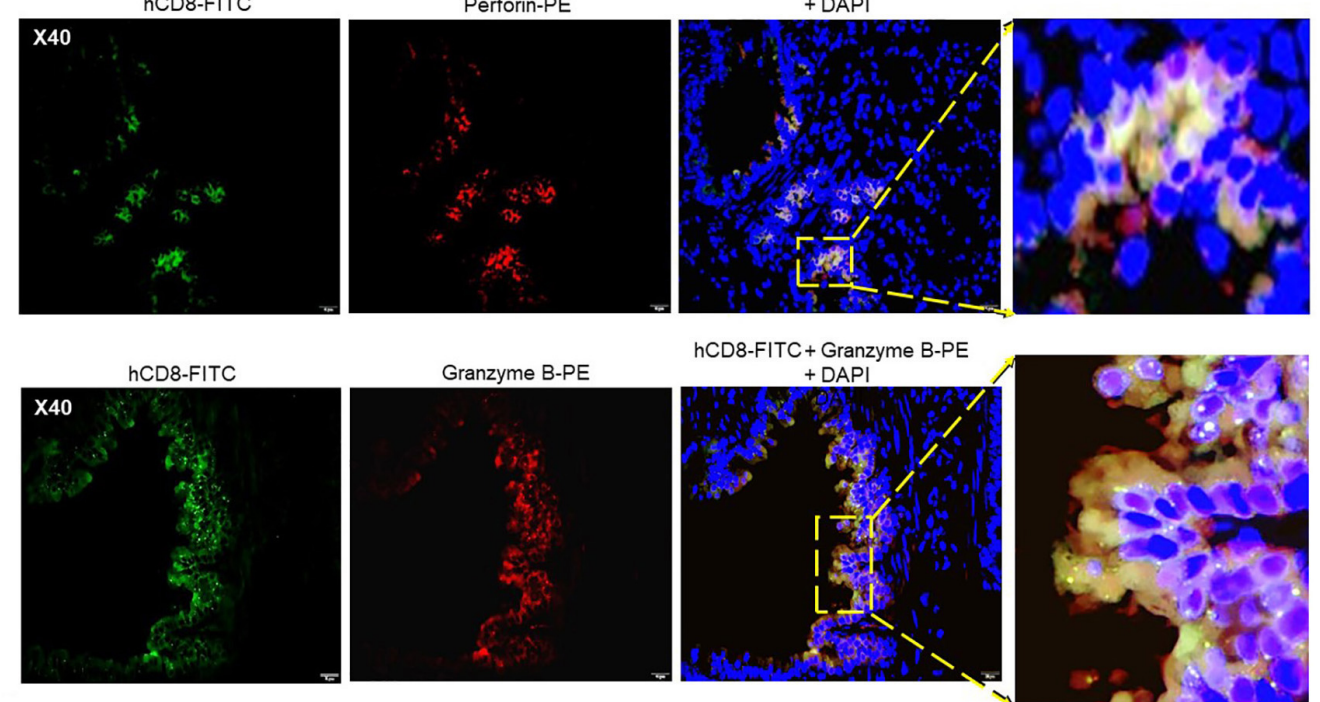

hCD8-FITC+ Granzyme B-PE

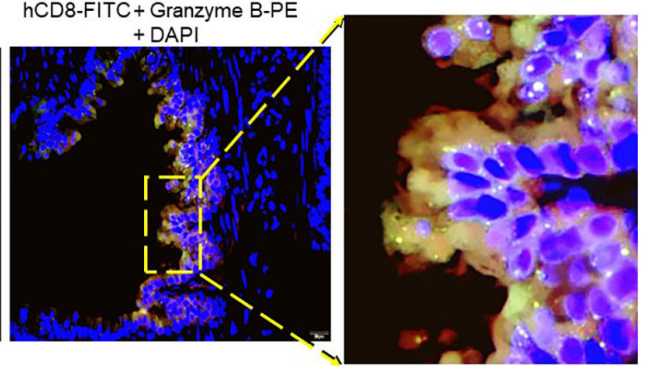

Fig. 6

Figure 6. hCD8 ${ }^{+} \mathrm{T}$-cell residency and cytotoxicity in the lung epithelial niches of a SARS-CoV-2infected HIS-DRAGA mouse. Shown are representative lung sections from mouse \#F2 infected with $2.8 \times 10^{3} \mathrm{pfu}$, which recovered its initial body weight at $9 \mathrm{dpi}$. a. Lung section co-stained with anti-hCD8$\mathrm{PE}$ and anti-hCD103-FITC (marker of lung residency). Enlargement shows a cluster of hCD8 ${ }^{+} \mathrm{hCD}^{103^{+}}$ $T$ cells sequestered in a lung alveolar niche. b. Lung section co-stained with the same antibodies. Enlargement shows several large epithelial niches containing hCD8 ${ }^{+} \mathrm{hCD} 103^{+} \mathrm{T}$ cells (orange), with some cells (orange) egressing into the alveolar air space. c. $\mathrm{hCD}^{+} \mathrm{T}$ cells clustered in the alveolar epithelial niches staining positive for perforin (orange). d. hCD8 ${ }^{+} \mathrm{T}$ cells from the same mouse (\#F2) sequestered throughout the alveolar epithelial niches and staining positive for Granzyme B (orange), with some egressing into the alveolar air space. 


\section{Table S1. Human immune parameters of HIS-DRAGA mice}

\begin{tabular}{|c|c|c|c|c|c|c|c|}
\hline & & & Perip & ral blood & & & \\
\hline Mouse* & Gender & $\begin{array}{l}\text { Time post- } \\
\text { infusion } \\
\text { with human } \\
\text { stem cells }\end{array}$ & $\begin{array}{l}\text { \% human B } \\
\text { cells } \\
\text { (CD19+) }\end{array}$ & $\begin{array}{l}\text { \% human T } \\
\text { cells } \\
\left(\mathrm{CD3}^{+}\right)\end{array}$ & $\begin{array}{l}\text { SARS-CoV-2 } \\
\text { challenge } \\
\text { dose (pfu) }\end{array}$ & $\begin{array}{l}\text { Euthanasia } \\
\text { (days post- } \\
\text { infection) }\end{array}$ & $\begin{array}{l}\text { Cord blood } \\
\text { HLA } \\
\text { haplotype^ }\end{array}$ \\
\hline M\#1 & $M$ & 21 weeks & 4.5 & 13.5 & $2.8 \times 10^{3}$ & 1(died) & A \\
\hline F\#1 & $\mathrm{F}$ & 21 weeks & 48.6 & 9.3 & $2.8 \times 10^{3}$ & 14 & A \\
\hline F\#2 & $F$ & 21 weeks & 21 & 33.4 & $2.8 \times 10^{4}$ & 14 & A \\
\hline F\#3 & $\mathrm{F}$ & 16 weeks & 9.0 & 2.5 & $1 \times 10^{3}$ & 25 & $B$ \\
\hline F\#4 & $\mathrm{F}$ & 16 weeks & 37.0 & 4.7 & $1 \times 10^{3}$ & 25 & $B$ \\
\hline F\#5 & $\mathrm{F}$ & 16 weeks & 23.6 & 5.0 & $1 \times 10^{3}$ & 25 & B \\
\hline F\#6 & $\mathrm{F}$ & 16 weeks & 0.6 & 12.5 & $1 \times 10^{3}$ & 25 & B \\
\hline F\#7 & $\mathrm{F}$ & 30 weeks & 5.9 & 42.6 & $1 \times 10^{3}$ & 25 & A \\
\hline F\#8 & $\mathrm{F}$ & 24 weeks & 16.1 & 37.8 & $1 \times 10^{3}$ & 25 & C \\
\hline F\#9 & $\mathrm{F}$ & 16 weeks & 21.5 & 8.0 & $1 \times 10^{3}$ & 25 & B \\
\hline F\#10 & $\mathrm{F}$ & 24 weeks & 6.0 & 23.8 & $1 \times 10^{3}$ & 25 & $C$ \\
\hline M\#2 & $M$ & 30 weeks & 8.3 & 9.3 & $1 \times 10^{3}$ & 3 & A \\
\hline M\#3 & $M$ & 16 weeks & 5.7 & 15.0 & $1 \times 10^{3}$ & 3 & B \\
\hline M\#4 & $\mathrm{M}$ & 16 weeks & 2.0 & 51.1 & $1 \times 10^{3}$ & 3 & $B$ \\
\hline F\#11 & $\mathrm{F}$ & 16 weeks & 6.1 & 25.4 & $1 \times 10^{3}$ & 3 & $\mathrm{~B}$ \\
\hline F\#12 & $\mathrm{F}$ & 24 weeks & 7.0 & 8.8 & $1 \times 10^{3}$ & 3 & $C$ \\
\hline F\#13 & $F$ & 24 weeks & 0.6 & 26.8 & $1 \times 10^{3}$ & 3 & C \\
\hline$a$ & $M$ & 20 weeks & 18.9 & 28.3 & ---- & ---- & $\mathrm{D}$ \\
\hline $\mathrm{b}$ & $M$ & 20 weeks & 0.9 & 41.4 & --- & ---- & $\mathrm{D}$ \\
\hline C & $F$ & 24 weeks & 52.5 & 17.5 & ---- & ---- & $\mathrm{D}$ \\
\hline$d$ & $M$ & 24 weeks & 7.4 & 16.6 & ---- & ---- & D \\
\hline $\mathrm{e}$ & $M$ & 24 weeks & 1.0 & 22.1 & ---- & ---- & $\mathrm{D}$ \\
\hline$f$ & $M$ & 24 weeks & 1.2 & 44.7 & ---- & ---- & $\mathrm{D}$ \\
\hline $\mathrm{g}$ & $M$ & 24 weeks & 17.6 & 38.3 & ---- & ---- & $\mathrm{D}$ \\
\hline $\mathrm{h}$ & $\mathrm{F}$ & 20 weeks & 35.2 & 5.0 & ---- & ---- & $E$ \\
\hline$i$ & $M$ & 26 weeks & 4.9 & 26.1 & ---- & ---- & $E$ \\
\hline j & $M$ & 26 weeks & 21.9 & 30.7 & ---- & ---- & $E$ \\
\hline
\end{tabular}

Lungs from uninfected mice a-j were pooled to assess human ACE2 mRNA and protein expression.
${ }^{\wedge} \mathrm{A}:$ A02:01/A24:02/B13:02/B44:02/DR01:01/DR04:01
^B: A01:01/A02:01/B08:01/B15:01/DR03:01/DR04:01
${ }^{\wedge} \mathrm{C}:$ A02:01/A24:02/B44:02/B52:01/DR04:01/DR11:04
${ }^{\wedge} \mathrm{D}:$ A02:01/A02:01/B18:01/B44:02/DR04:01/DR11:04
${ }^{\wedge} \mathrm{E}:$ 02:01/A02:01/B08:01/B27:05/DR03:01/DR04:01 


\section{hACE2 protein levels in HIS-DRAGA mouse vs. human lungs}

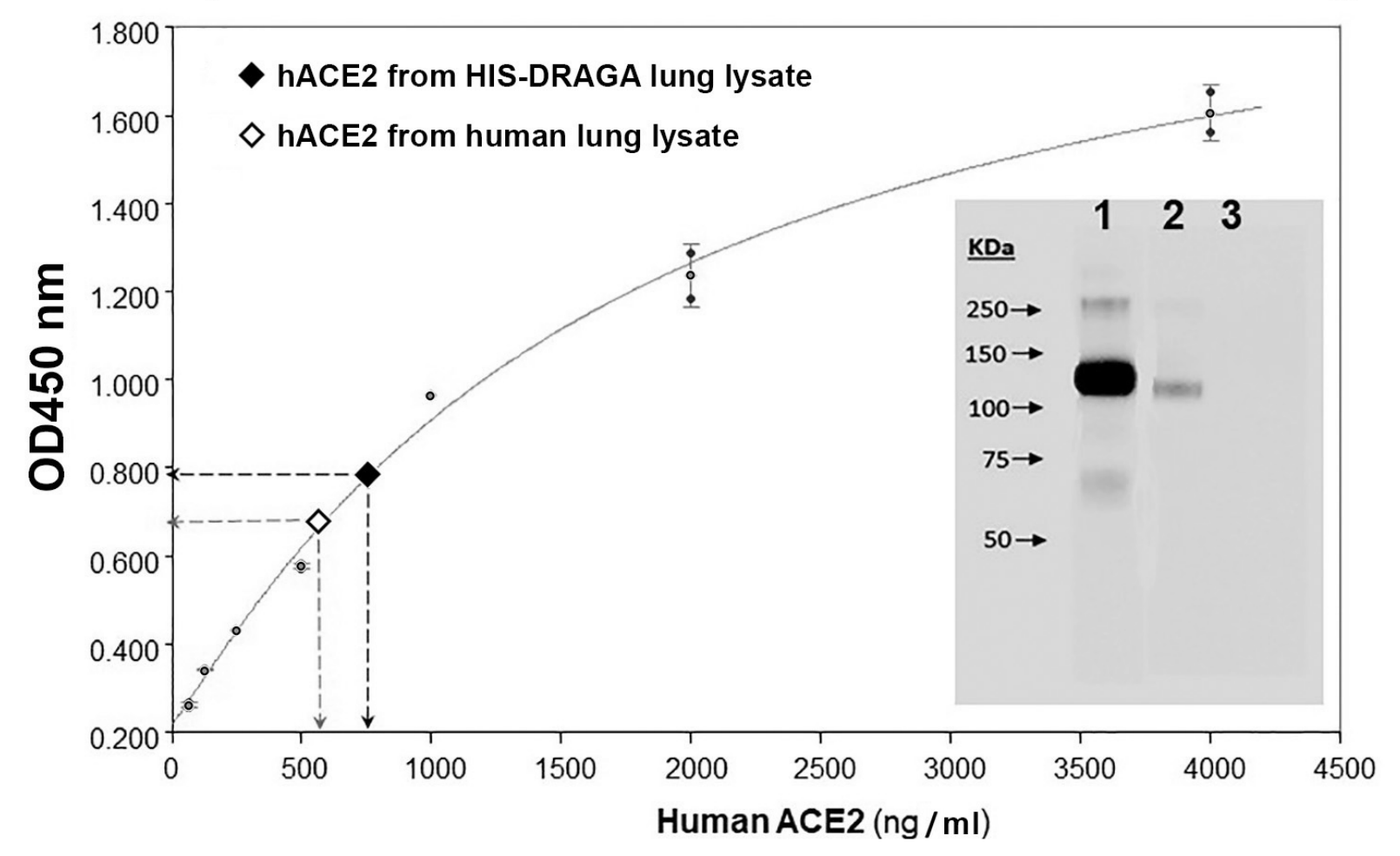

\begin{tabular}{|c|c|c|c|c|}
\hline Sample & $\begin{array}{c}\text { Concentrated } \\
\text { immunoprecipitate }\end{array}$ & $\begin{array}{c}\text { [hACE2] } \\
\text { from ELISA }\end{array}$ & dilution & $\begin{array}{c}\text { [hACE2] in total lung } \\
\text { protein }\end{array}$ \\
\hline $\begin{array}{c}2 \mathrm{mg} \text { Human } \\
\text { lung protein }\end{array}$ & $52 \mu \mathrm{l}$ & $655 \mathrm{ng} / \mathrm{ml}$ & $1: 100$ & $1.703 \mu \mathrm{g} / \mathrm{mg}$ \\
\hline $\begin{array}{c}9 \mathrm{mg} \text { HIS-DRAGA } \\
\text { lung protein }\end{array}$ & $52 \mu \mathrm{l}$ & $757 \mathrm{ng} / \mathrm{ml}$ & $1: 50$ & $0.219 \mu \mathrm{g} / \mathrm{mg}$ \\
\hline $\begin{array}{c}9 \mathrm{mg} \text { DRAGA } \\
\text { lung protein }\end{array}$ & $52 \mu \mathrm{l}$ & ND* & $1: 50$ & ND* \\
\hline
\end{tabular}

*ND = Not Detectable

Ratio [hACE2] in human lung / [hACE2] in HIS-DRAGA mouse lung (ELISA) $=7.8$

Fig. S1

Figure S1. Quantification of hACE2 protein in HIS-DRAGA lungs. Human ACE2 levels in immunoprecipitates obtained from non-infected HIS-DRAGA and human lung lysates using $\mathrm{S} 1(\mathrm{RBD})-\mathrm{mFc} 2 \mathrm{2a}$ protein + rat anti-mouse IgG2a-magnetic beads were quantified by ELISA. Of note, the OD450nm values for protein immunoprecipitated from a pool of 10 non-infected, non-HIShumanized DRAGA mouse lung lysates (negative control) fell below the limit of detection (OD450nm $<0.05$ ). Insert shows Western blot detection of hACE2 protein in the concentrated immunoprecipitates probed with a mouse monoclonal anti-human ACE2 IgG followed by goat antimouse IgG-HRP with ECL detection. Lane 1, human lung immunoprecipitate; lane 2, HIS-DRAGA mouse lungs immunoprecipitate; lane 3, DRAGA mouse lungs immunoprecipitate (note this sample did not contain detectable hACE2). Lower panel shows the experimental conditions for immunoprecipitation of hACE2, quantification by ELISA, and the ratio of hACE2 in human versus HIS-DRAGA mouse lung samples. 


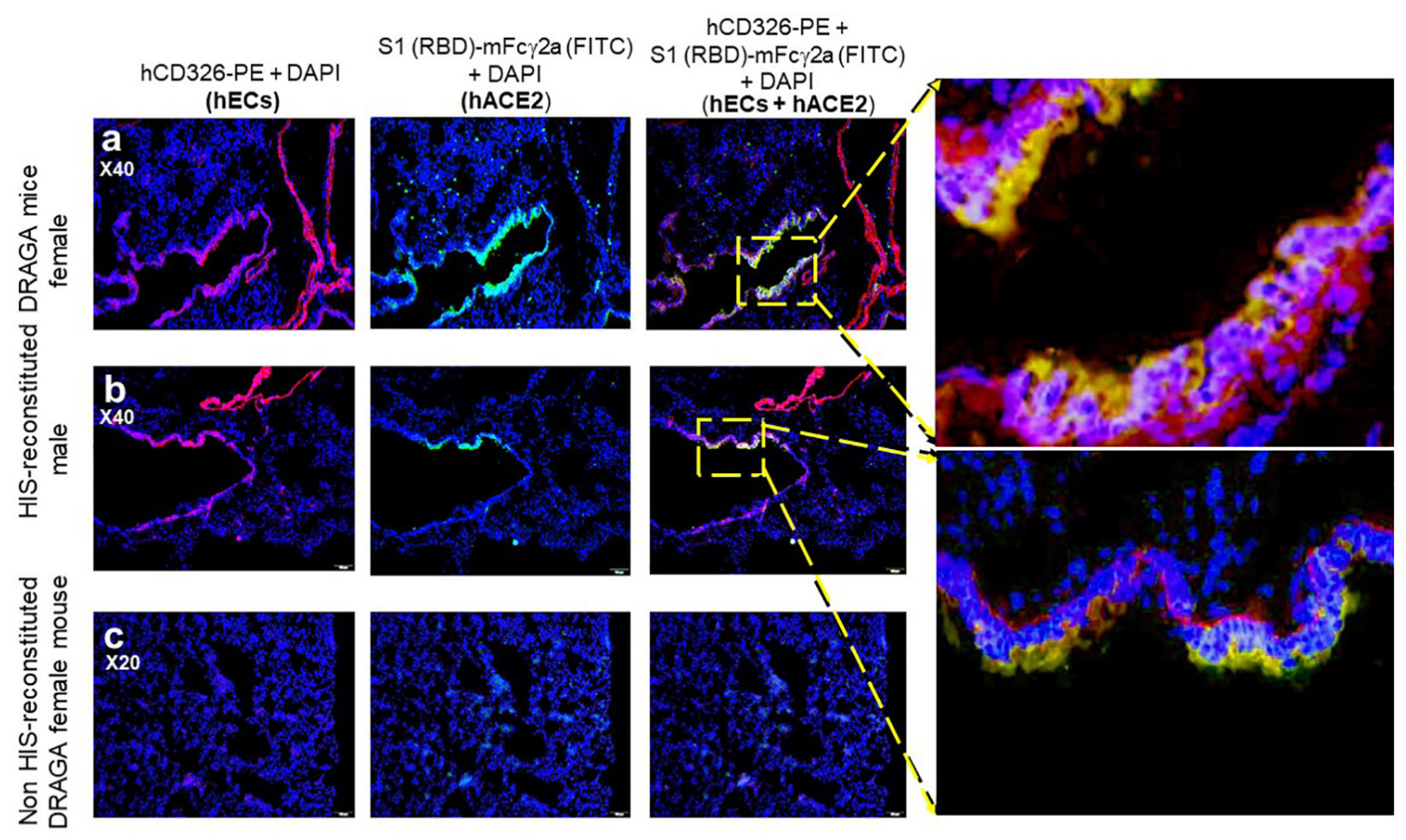

Fig. S2

Figure S2. Co-localization of hACE2 receptor with hCD326 ${ }^{+}$alveolar ECs in a non-infected HISDRAGA mouse. a,b. Co-localization of hACE2 with alveolar hCD $326^{+}$ECs (orange) revealed by costaining of S1(RBD)-mFc 2a protein + goat anti-mouse IgG-FITC (green) and anti-hCD326-PE (red) in representative HIS-DRAGA female and male mice. c. Lack of $\mathrm{hCD} 326^{+} \mathrm{ECs}$ and negligible binding of $\mathrm{S} 1$ (RBD)-mFc 2a protein to a representative lung section from a non-HIS-reconstituted DRAGA female mouse. 
HIS-DRAGA female mouse

a $\mathrm{S} 1$ (RBD)-mFc $2 \mathrm{a}(\mathrm{FITC})+\mathrm{DAPI}$
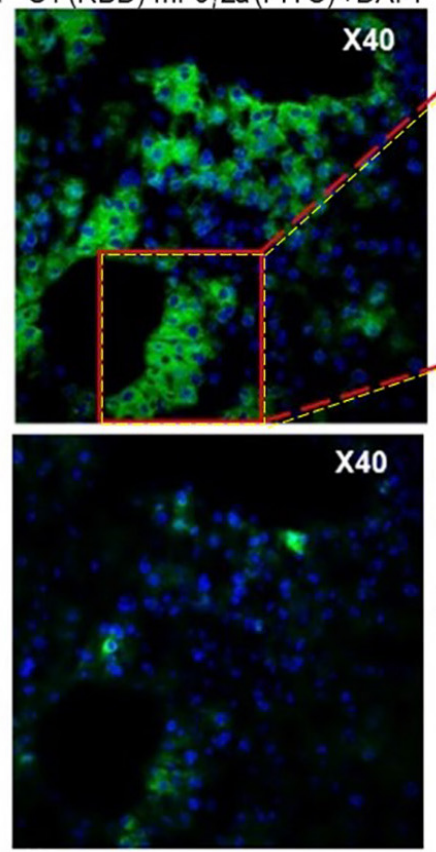

HIS-DRAGA male mouse

b
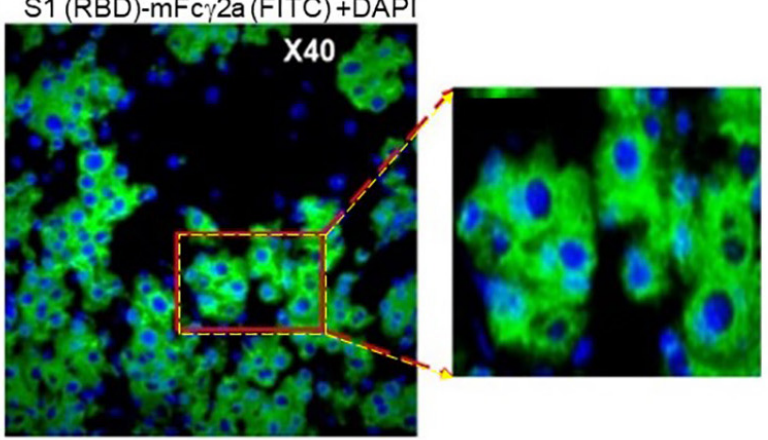

$\mathbf{X} 40$

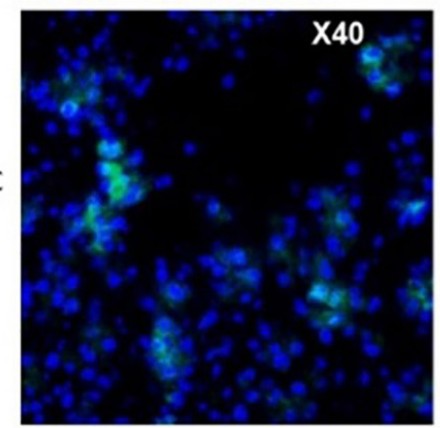

Fig. S3

Figure S3. Binding of SARS-CoV-2 S1(RBD) protein to the endothelium of liver cholangiocytes in non-infected HIS-DRAGA mice. S1(RBD) binding to the liver cholangiocytes from representative non-infected HIS-DRAGA female (panel a) and male (panel b) mice. Merged images and enlargements show binding of S1(RBD)-mFc 2a revealed by a goat anti-mouse IgGFITC conjugate (green) and nuclei (DAPI, blue). Lower panels, representative images showing minimal background binding of the goat anti-mouse IgG-FITC secondary antibody (green) and nuclei (DAPI, blue) in tissues from the same mice in panels $a$ and $b$. 


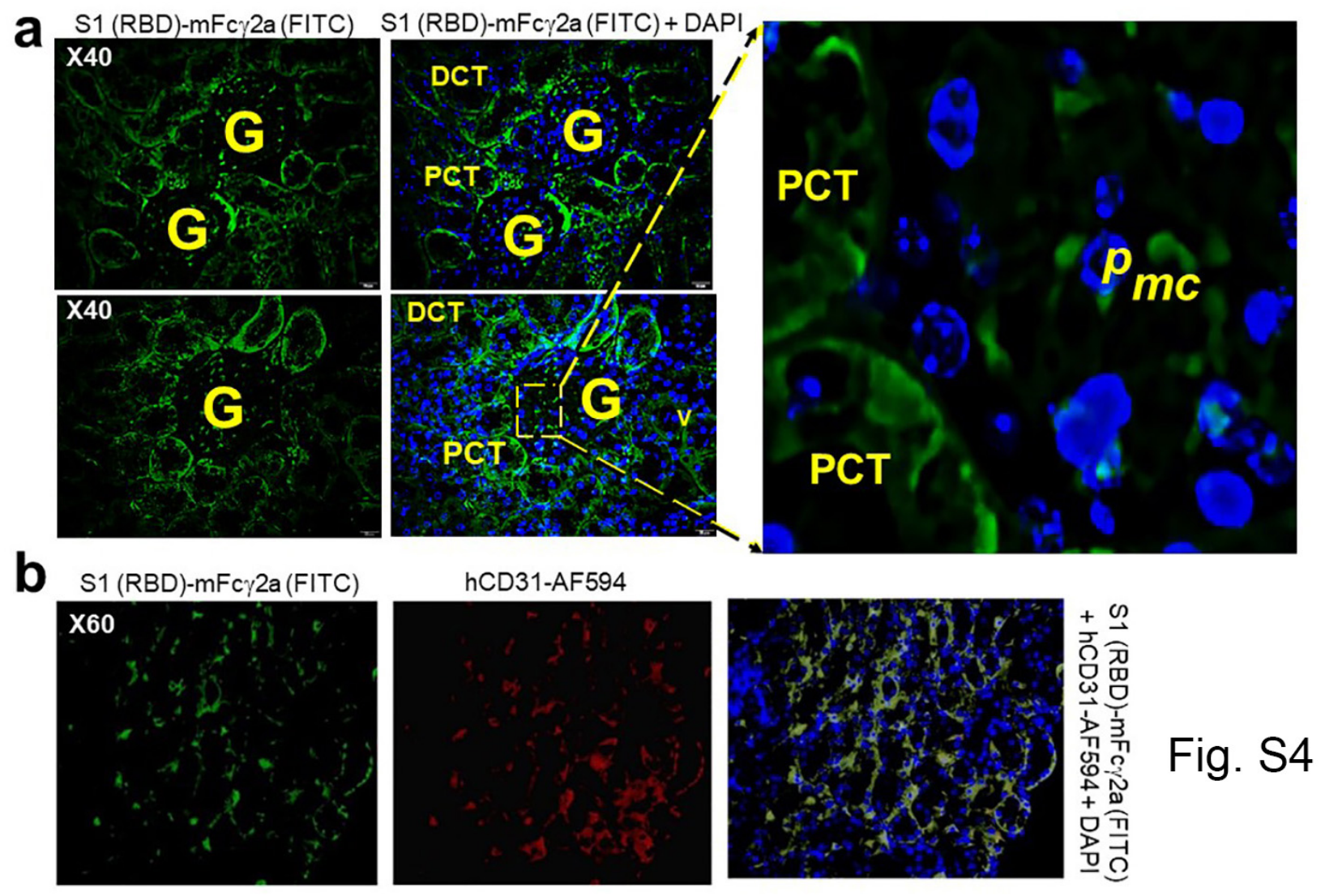

Figure S4. Binding of SARS-CoV-2 S1 (RBD) protein to kidney epi/endothelia of infected HISDRAGA mice. a. Sections of renal cortex from HIS-DRAGA survivors \#F1 (upper panels) and \#F2 (lower panels) of SARS-CoV-2 infection with $2.8 \times 10^{4}$ pfu and $2.8 \times 10^{3}$ pfu, respectively, at the experimental endpoint (14 dpi). Sections were co-stained with DAPI (blue) and S1(RBD)-mFc 2a protein + goat antimouse IgG-FITC (green). Shown is the S1(RBD) protein bound to the epithelium layer of proximal convoluted tubules (PCT) and distal convoluted tubules (DCT) surounding the glomeruli (G). Enlargement of a peripheral glomerular area shows nuclei (blue) of podocytes (p) and the endothelia (green) of glomerular microcapilaries $(\mathrm{mc})$ in close proximity to the podocytes (green). b. Expression of hACE2 revealed by S1(RBD)-mFc 2a binding (green) on kidney epithelial cells labeled with an antihCD31-AF594 antibody (red). 


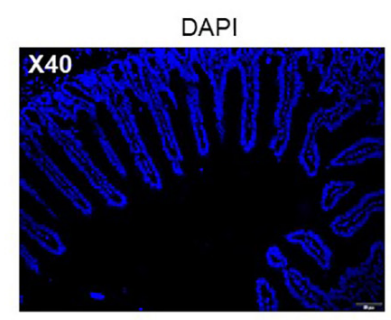

$\mathrm{S} 1(\mathrm{RBD})-\mathrm{mFc} \gamma 2 \mathrm{a}(\mathrm{FITC})$

$\mathrm{S} 1$ (RBD)-mFc $\gamma 2 \mathrm{a}(\mathrm{FITC})+\mathrm{DAPI}$
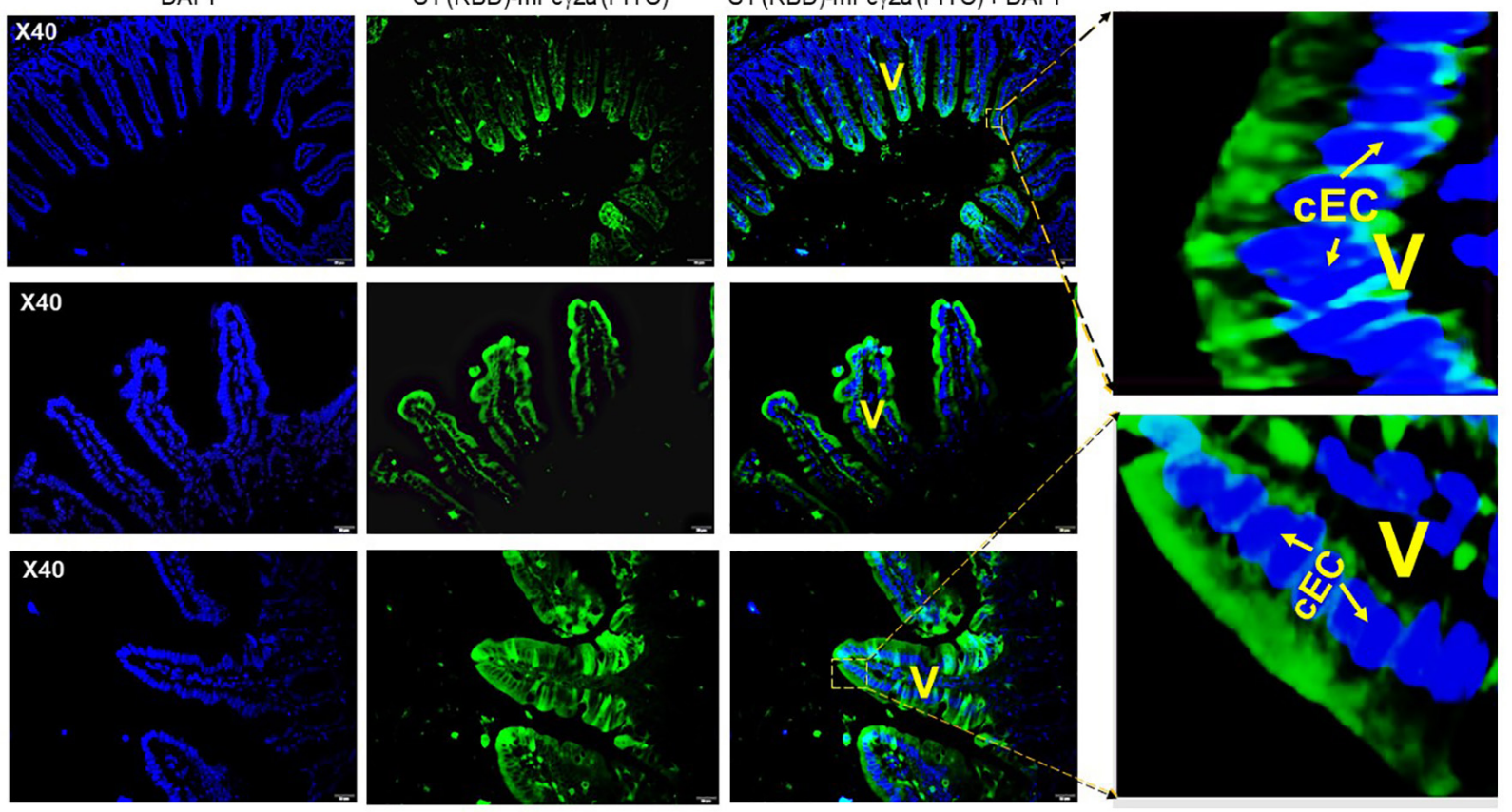

Fig. S5

Figure S5. Binding of SARS-CoV-2 S1(RBD) protein to intestinal epithelia of infected HISDRAGA mice. Tissue sections from the small intestine of HIS-DRAGA mouse \#F1 (upper and middle pane/s) and \#F2 (lower panel) survivors of SARS-CoV-2 infection with $2.8 \times 10^{4}$ pfu and $2.8 \times 10^{3}$ pfu, respectively, at the experimental endpoint (14 dpi). Sections were co-stained with DAPI (nuclei, blue) and S1(RBD)-mFc 2a protein+ goat anti-mouse IgG-FITC (green). Shown is the S1(RBD) protein bound to the columnar epithelial cells (cEC) of the absorptive intestinal villi $(\mathrm{V})$. 
DAPI
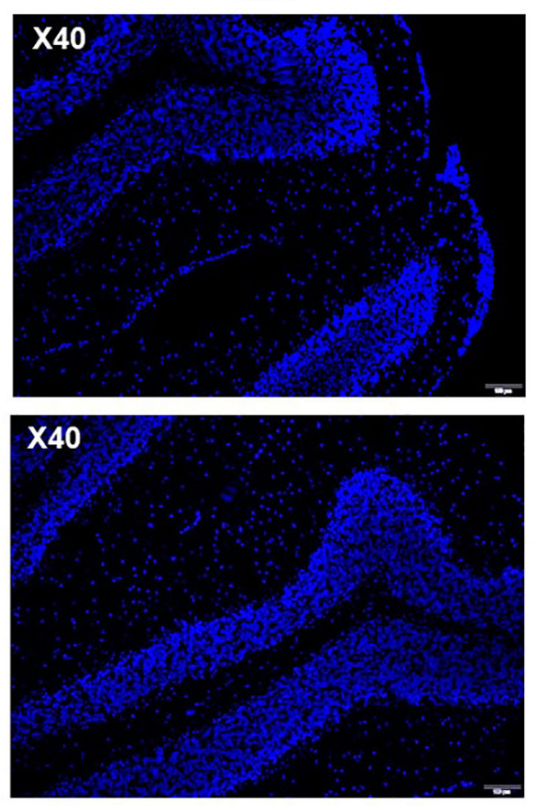

$\mathrm{S} 1(\mathrm{RBD})-\mathrm{mFc} \gamma 2 \mathrm{a}(\mathrm{FITC})$
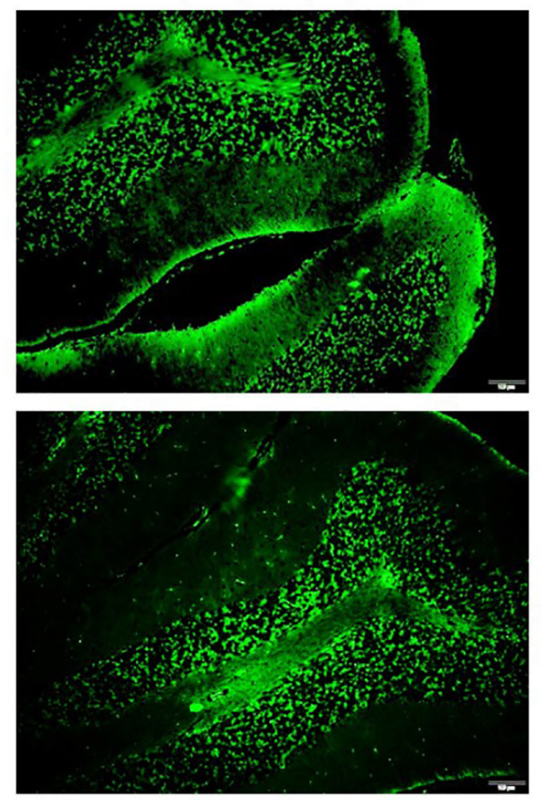

$\mathrm{S} 1(\mathrm{RBD})-\mathrm{mFc} 2 \mathrm{2a}(\mathrm{FITC})+\mathrm{DAPI}$
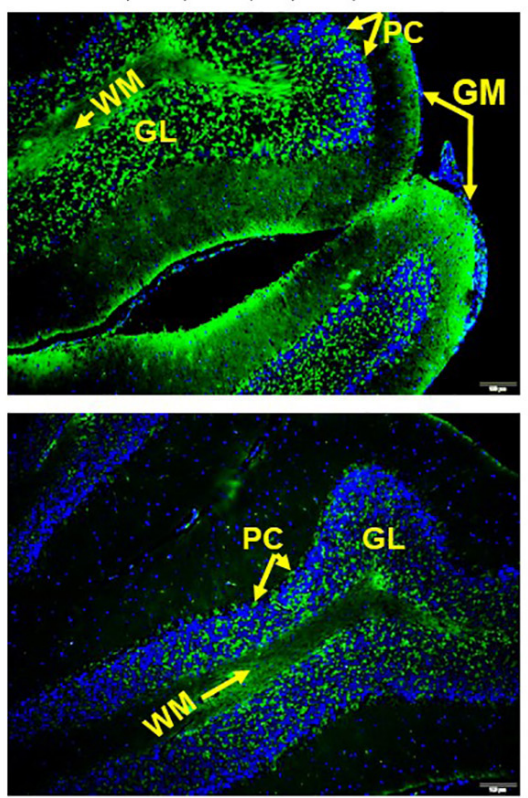

Fig. S6

Figure S6. Binding of SARS-CoV-2 S1(RBD) protein to the brain epithelia in infected HIS-DRAGA mice. Tissue sections of cerebellum cortex from HIS-DRAGA mice \#F1 (upper panel) and \#F2 (lower panel) survivors of SARS-CoV-2 infection with $2.8 \times 10^{4} \mathrm{pfu}$ and $2.8 \times 10^{3} \mathrm{pfu}$, respectively, at the experimental endpoint (14 dpi) co-stained with DAPI (nuclei, blue) and S1(RBD)-mFc 2a protein + goat anti-mouse IgG-FITC (green). Shown is the S1(RBD) protein bound to the white matter (WM), granular layer (GL), and Purkinje cells (PC), but not to the outer neuronal layer in the grey matter (GM). 
bioRxiv preprint doi: https://doi.org/10.1101/2020.08.19.251249; this version posted January 29, 2021. The copyright holder for this preprint (which was not certified by peer review) is the author/funder. This article is a US Government work. It is not subject to copyright under 17 USC 105 and is also made available for use under a CCO license.
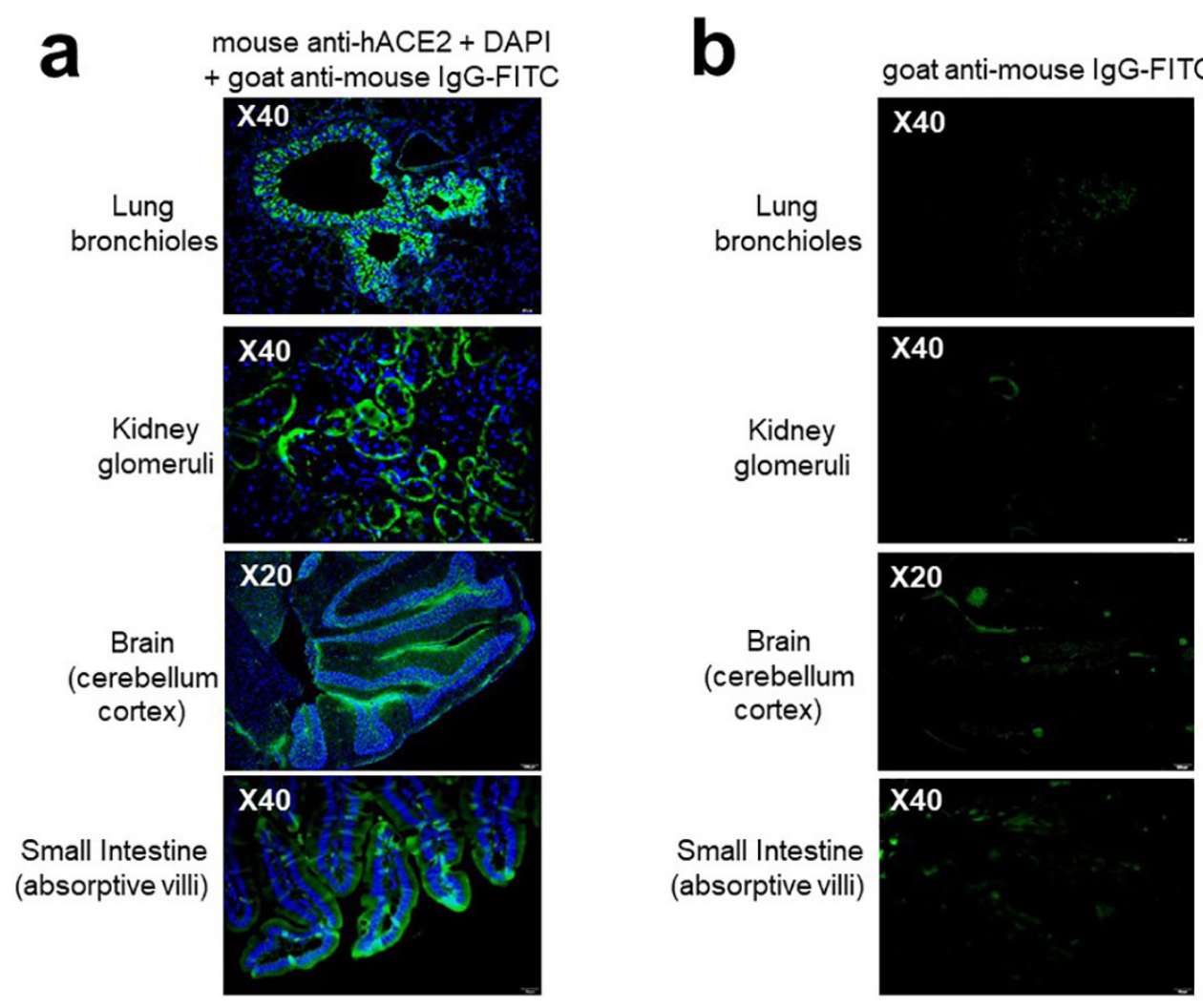

goat anti-mouse IgG-FITC
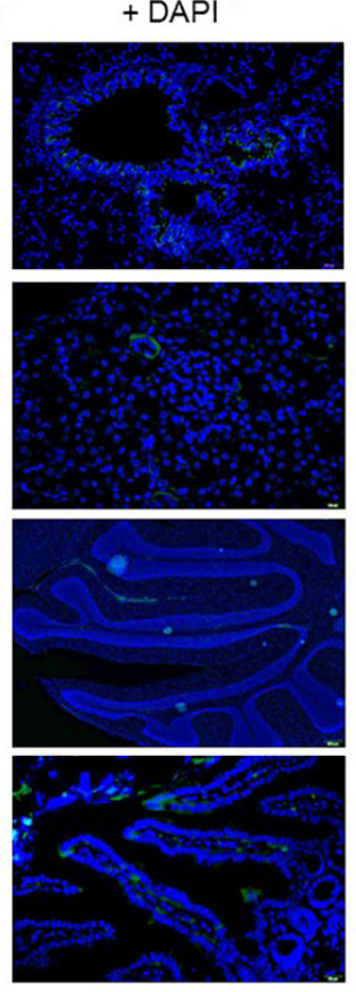

Fig. S7

Figure S7. Identification of hACE2 on tissue sections from organs of a non-infected HIS-DRAGA mouse, detected with an anti-hACE2 specific antibody. a. Merged images of tissue sections from a representative non-infected HIS-DRAGA mouse stained with mouse anti-hACE2 followed by goat anti-mouse IgG-FITC (green) and DAPI (blue). b. Minimal background binding of the secondary antibody (goat anti-mouse IgG-FITC) (left) overlapped with DAPI staining (right) of tissue sections adjacent to those shown in panel $a$. 


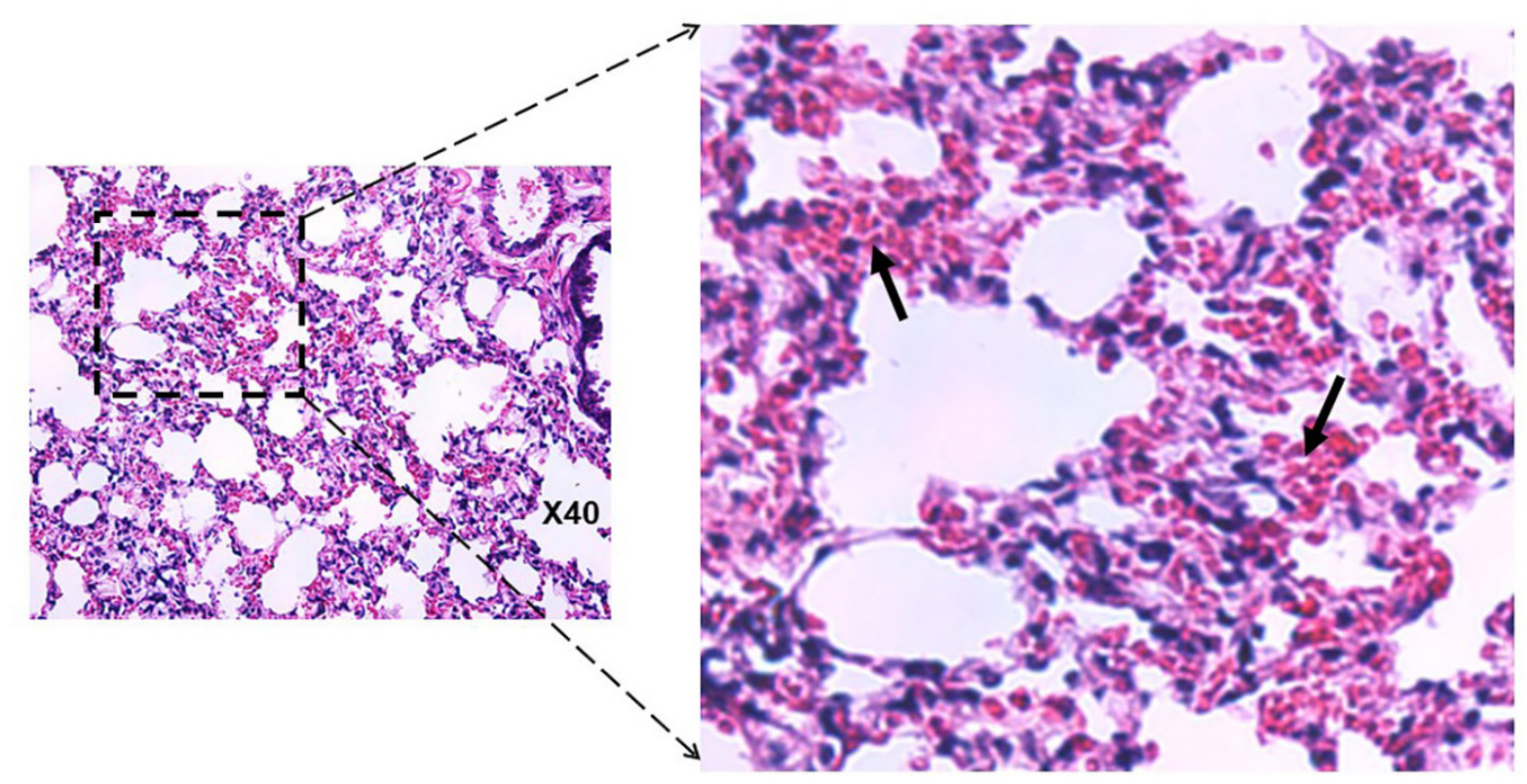

Fig. S8

Figure S8. Lung pathology of a HIS-DRAGA mouse recovering from SARS-CoV-2 infection. Representative H\&E-stained lung section from HIS-DRAGA mouse \#F2 that recovered its initial body weight at 9 days after infection with SARS-CoV-2 at $2.8 \times 10^{3}$ pfu. Interstitial and intra-alveolar infiltrates are indicated by arrows. 
CD61-PE

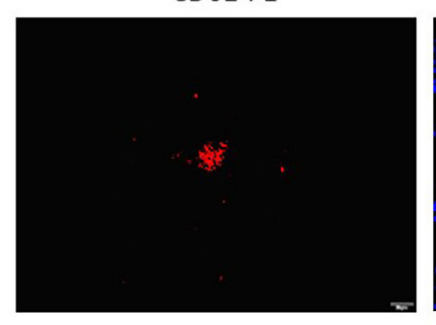

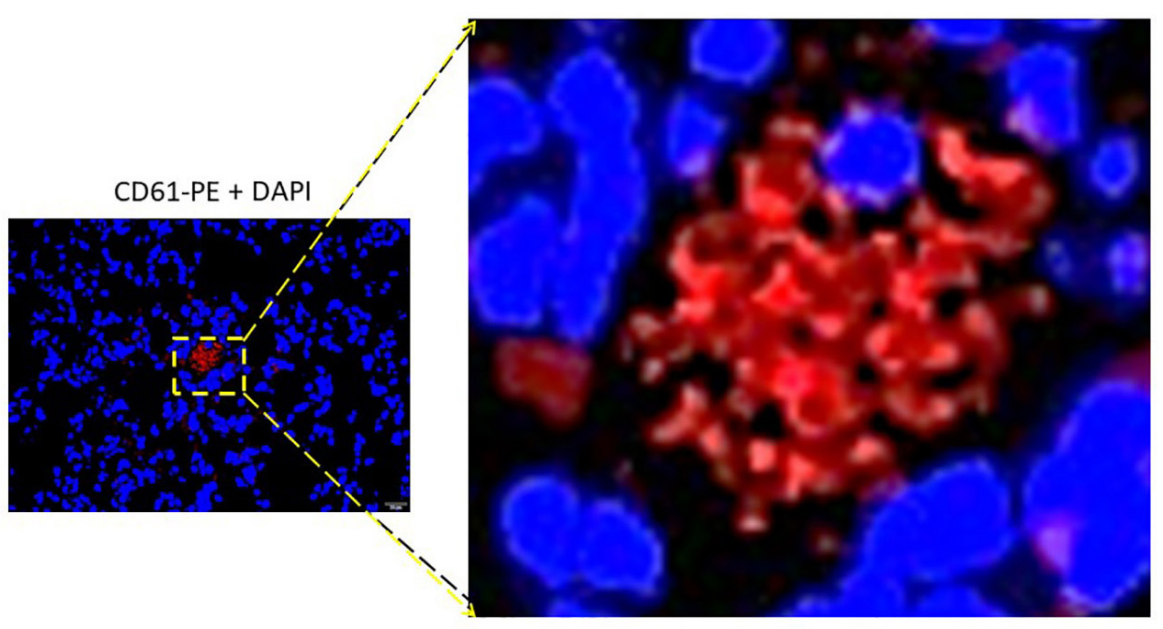

Fig. S9

Figure S9. CD61+ intra-alveolar microthrombi in a SARS-CoV-2 infected HIS DRAGA mouse. Intraalveolar microthrombi in lung section from a HIS-DRAGA mouse infected with $2.8 \times 10^{4}$ pfu of SARS-CoV2 , which had not recovered its initial body weight by $14 \mathrm{dpi}$. Left panel, staining with anti-CD61-PE (red). Right panel with enlargement: merged anti-CD61-PE co-staining with DAPI (blue). The non-nucleated $\mathrm{CD} 61^{+}$cluster indicates this is a platelet micro-thrombus. 
bioRxiv preprint doi: https://doi.org/10.1101/2020.08.19.251249; this version posted January 29, 2021. The copyright holder for this preprint (which was not certified by peer review) is the author/funder. This article is a US Government work. It is not subject to copyright under 17 USC 105 and is also made available for use under a CCO license.
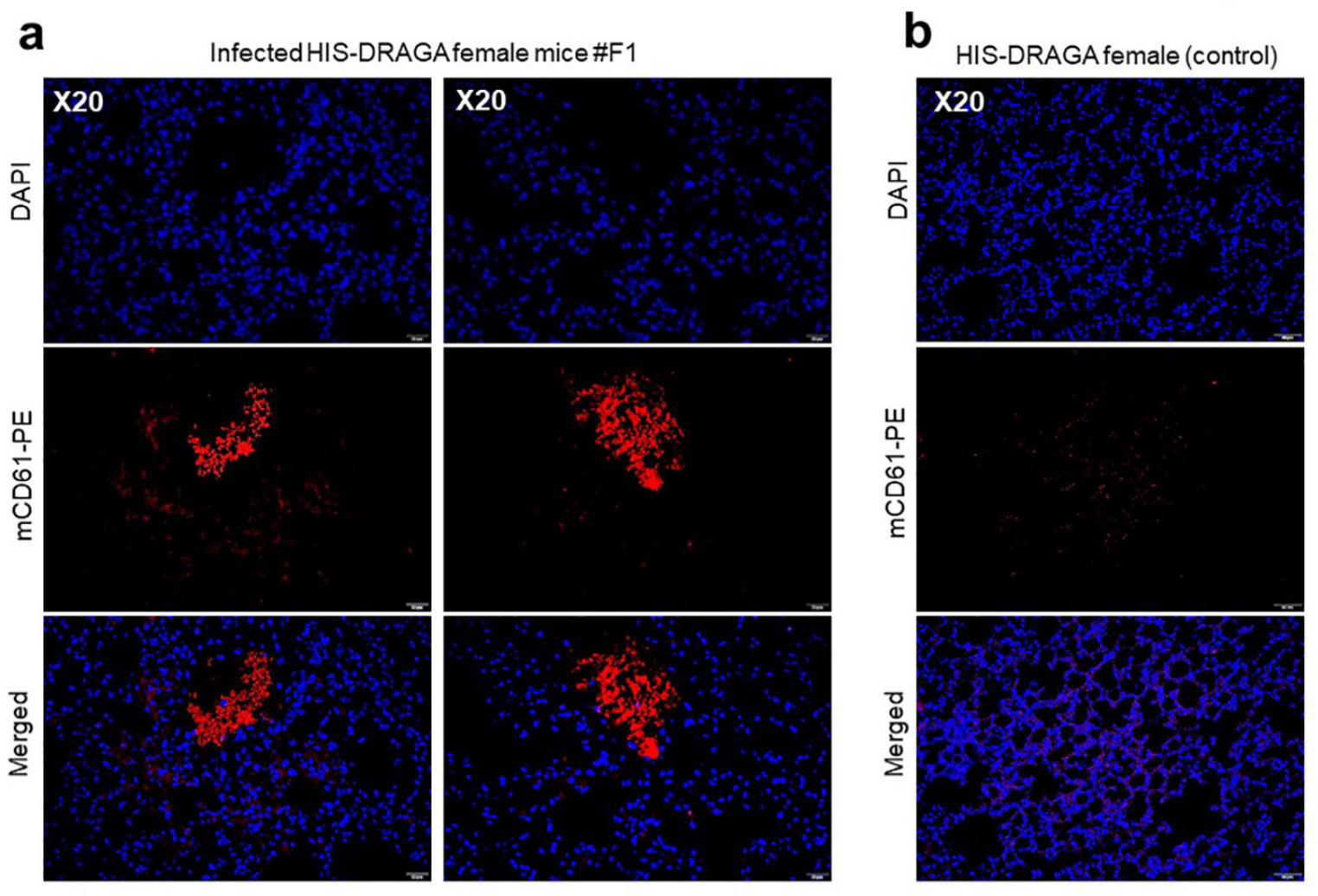

\section{Fig. S10}

Figure S10. Large intra-alveolar thrombi in a SARS-CoV-2 infected HIS-DRAGA mouse. a.

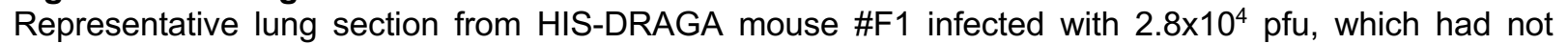
recovered its initial body weight by $14 \mathrm{dpi}$. Co-staining with anti-CD61-PE (red) + DAPI (blue). b. Representative lung section from a non-infected HIS-DRAGA mouse stained as in panel a, with no evidence of intra-alveolar thrombi. 

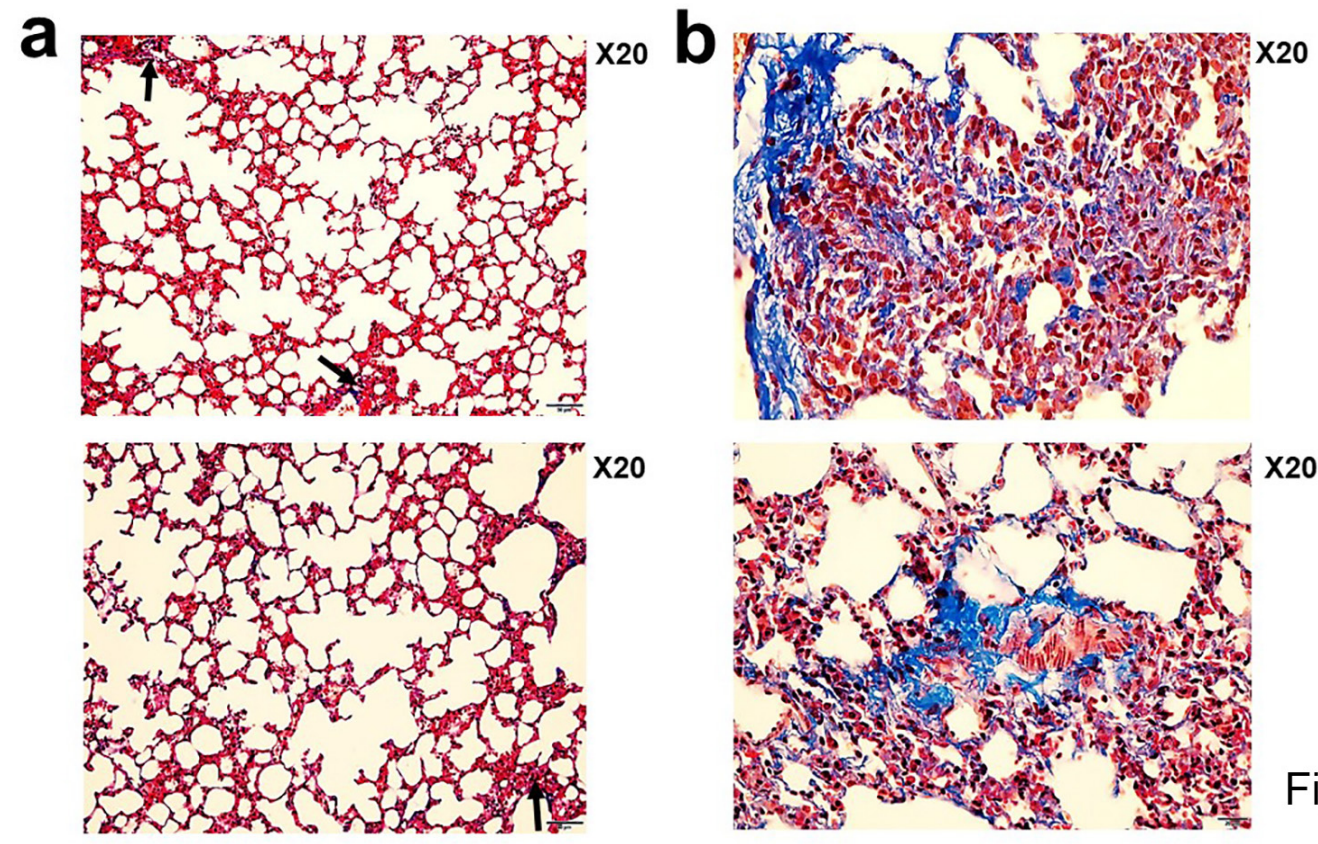

Fig. S11

Figure S11. Pulmonary sequelae in SARS-CoV-2 infected DRAGA mice. a. Masson's Trichrome staining of lung sections from HIS-DRAGA mice \#F3 (upper panel) and \#F4 (lower panel) infected with $10^{3}$ pfu SARS-CoV-2, which recovered their initial body weights by 9 and $25 \mathrm{dpi}$, respectively. Shown are small peri-alveolar infiltrates building collagen fibers (blue, arrows). b. Masson's Trichrome staining of lung sections from HIS-DRAGA mice \#F5 (upper panel) and \#F6 (lower panel) infected with $10^{3}$ pfu SARS-CoV-2, which had not recovered their initial body weights by 25 dpi. Shown are peri-alveolar and intra-alveolar infiltrated areas building collagen fibers (blue). 

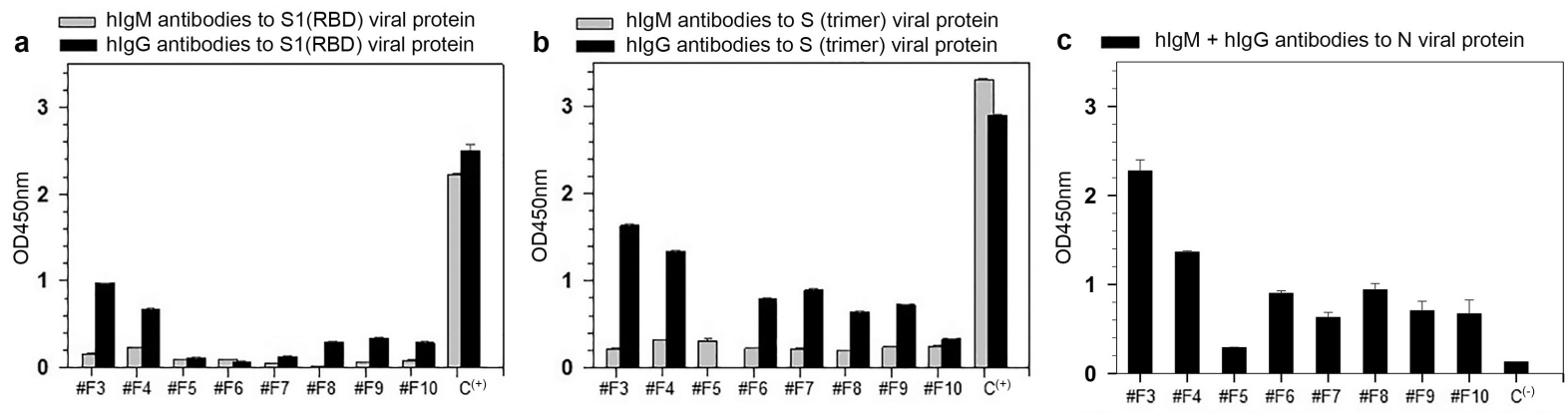

Fig. S12

Figure S12. Antibody serum titers to SARS-CoV-2 viral proteins. Titers of hlgM and hlgG antibodies to $S 1(R B D)$ protein (a) S-trimer protein $(\boldsymbol{b})$ and $N$ protein (c) in sera (diluted 1:20) from 8 HIS-DRAGA mice infected with SARS-CoV-2 (10 $\left.10^{3} \mathrm{pfu}\right)$, as measured by ELISA at $25 \mathrm{dpi}$. An anti-S1(RBD) antibody provided in the kit (Bethyl Laboratories) was included as a positive control in panels a and $b(C+)$. The antibody titers against the $\mathrm{N}$ protein in serum from a non-infected mouse served as a negative control in panel c. OD450nm values were corrected by subtracting values (ranging from 0.045-0.067) of serum samples from the same mice prior to infection. Standard deviations (+/-SD) for each serum sample in duplicate wells were determined at $99 \%$ interval of confidence by SigmaPlot v. 14 software. 
bioRxiv preprint doi: https://doi.org/10.1101/2020.08.19.251249; this version posted January 29, 2021. The copyright holder for this preprint (which was not certified by peer review) is the author/funder. This article is a US Government work. It is not subject to copyright under 17 USC 105 and is also made available for use under a CCO license.

\section{KEY REAGENTS AND RESOURCES}

\begin{tabular}{|c|c|c|}
\hline Kits, Recombinant proteins and Chemicals & Source & Catalog \# \\
\hline EasySep Human CD3 Positive Selection Kit & Stem Cell Technologies, Vancouver, BC, Canada & 18051 \\
\hline Qiagen RNA Extraction Kit & Qiagen, Hilden, Germany & 74104 \\
\hline Human lung mRNA & Thermo FIsher Scientific, Waltham, MA, USA & AM7968 \\
\hline One-Step RT-PCR kit & Qiagen, Hilden, Germany & 210210 \\
\hline MPER mammalian protein extraction reagent & Thermo Fisher Scientific, Waltham, MA, USA & 78501 \\
\hline Complete protease inhibitor cocktail tablets & Roche Diagnostics $\mathrm{GmbH}$, Mannheim, Germany & 1186153001 \\
\hline Ceramic beads & MP Biologicals, Irvine, CA, USA & 6913100 \\
\hline Fast-prep homogenizer & MP Biologicals, Irvine, CA, USA & SKU 116005500 \\
\hline BCA reagent & Thermo Fisher Scientific, Waltham, MA, USA & 23225 \\
\hline S1(RBD)-mFcgamma2a chimeric antibody & ACRO Biosystems, Newark, DE, USA & S1N-C5257 \\
\hline Rat anti-mouse IgG2a-magnetic microbeads & Miltenyi Biotec, Berdisch Gladback, Germany & $130-047-202$ \\
\hline MACS magnetic columns & Miltenyi Biotec, Berdisch Gladback, Germany & $130-042-401$ \\
\hline SARS-CoV-2 S protein, His Tag, Super stable trimer & ACRO Biosystems, Newark, DE, USA & SPN-C52H9 \\
\hline SARS-CoV-2 N protein, His Tag & ACRO Biosystems, Newark, DE, USA & NUN-C51H9 \\
\hline Bovine serum al bumin (BSA) & Sigma-Aldrich, St. Louis, MO, USA & A7030-100g \\
\hline SuperSignal ${ }^{\mathrm{TM}}$ West Pico PLUS Chemiluminescent Substrate & Thermo Fisher Scientific, Waltham, MA, USA & 34579 \\
\hline NuPAGE $^{\text {TM }} 4$ to $12 \%$, Bis-Tris, $1.5 \mathrm{~mm}$, Mini Protein Gel, 10-well & Thermo Fisher Scientific, Waltham, MA, USA & NP0335PK2 \\
\hline Human lung total protein & Zyagen, San Diego, CA, USA & HT -601 \\
\hline iBlot ${ }^{\mathrm{TM}} 2 \mathrm{Gel}$ Transfer Device & Thermo Fisher Scientific, Waltham, MA, USA & IB21001 \\
\hline Vectashield containing DAPI & Vector Laboratories, Burlingame, CA, USA & $\mathrm{H}-1200-10$ \\
\hline Tissue fixation/permeabilization buffer & Thermo Fisher Scientific, Waltham, MA, USA & $00-8333-56$ \\
\hline microplate reader & BioTek Instruments, Winooski, VT, USA & \\
\hline Fluorchem E imaging system & ProteinSimple, San Jose, CA, USA & \\
\hline RNA-STAT-60 extraction reagent & Tel-Test, Inv., Friendswood, TX, USA & TL-4200 \\
\hline RT-qPCR primers + probe for SARS-CoV-2 Nucleocapsid RNA & Integrated DNA Technologies, Coralville, IA, USA & none \\
\hline RT-qPCR kit & Meridian Bioscience, Memphis, TN, USA & BIO-78005 \\
\hline
\end{tabular}


bioRxiv preprint doi: https://doi.org/10.1101/2020.08.19.251249; this version posted January 29, 2021. The copyright holder for this preprint

(which was not certified by peer review) is the author/funder. This article is a US Government work. It is not subject to copyright under 17 USC 105 and is also made available for use under a CCO license.

\begin{tabular}{|c|c|c|}
\hline Antibodies & Source & Catalog \# \\
\hline Mouse monoclonal antibody to hACE2 & Abcam, Cambridge, MA, USA & Ab-89111 \\
\hline Mouse anti-human CD3-FITC & BD Biosciences, SanJose, CA, USA & 555339 \\
\hline Mouse anti-human CD45-FITC & BD Biosciences, SanJose, CA, USA & 347463 \\
\hline Mouse anti-human CD8-PE & BD Biosciences, SanJose, CA, USA & 555635 \\
\hline Mouse anti-human granzyme-B-PE & BD Biosciences, SanJose, CA, USA & 561142 \\
\hline Recombinant human anti-human CD326-PE & Miltenyi Biotec, Berdisch Gladback, Germany & 130-110-999 \\
\hline Mouse anti-human Perforin-PE & Biolegend, San Diego, CA, USA & 353304 \\
\hline Mouse anti-human CD103-FITC & BD Pharmingen, Irvine, CA, USA & 550259 \\
\hline Hamster anti-mouse CD61-PE & Thermo Fisher Scientific, Waltham, MA, USA & $12-0611-82$ \\
\hline Mouse anti-human CD31-Alexa Fluor 594 & Biolegend, San Diego, CA, USA & 303126 \\
\hline Anti-human TMPRSS2 Antibody & Sigma-Aldrich, St. Louis, MO, USA & MABF2158-100UG \\
\hline Goat anti-Mouse lgG FC-FITC & Southem Biotech, Birmingham, AL, USA & $1013-02$ \\
\hline Goat anti mouse lgG-HRP & Santa Cruz Biotechnology, Dallas, TX, USA & Sc-2005 \\
\hline Goat $F\left(a b^{\prime}\right) 2$ anti-mouse $\lg G 2 a$, Human ads-FITC & Southem Biotech, Birmingham, AL, USA & $1082-02$ \\
\hline Goat $F\left(a b^{\prime}\right) 2$ anti-mouse lgG1, Human ads-PE & Southem Biotech, Birmingham, AL, USA & $1072-09$ \\
\hline Anti-human IgM antibody-HRP & Bethyl Laboratories, Montgomery, TX, USA & A80-100P \\
\hline Anti-human IgG antibody-HRP & Bethyl Laboratories, Montgomery, TX, USA & A80-104P \\
\hline Anti-human kappa antibody-HRP & Bethyl Laboratories, Montgomery, TX, USA & A80-115P \\
\hline Anti-human lambda antibody-HRP & Bethyl Laboratories, Montgomery, TX, USA & A80-116P \\
\hline
\end{tabular}

\begin{tabular}{|l|l|l|}
\hline ELISA Kits and supplies & Source & Catalog \# \\
\hline Human ACE2 ELISA kit PicoKine & Boster Biological Technology, Pleasanton, CA, USA & EK0997 \\
\hline SARS-CoV-2 IgM ELISA Kit (antigen is rS1(RBD) & Bethyl Laboratories, Montgomery, TX, USA & E88-302 \\
\hline SARS-CoV-2 lgG ELISA Kit (antigen is rS1(RBD) & Bethyl Laboratories, Montgomery, TX, USA & E88-301 \\
\hline Coming Costar high-binding ELISA plates & Thermo Fisher Scientific, Waltham, MA, USA & $07-200-721$ \\
\hline
\end{tabular}

Biological samples

Umbilical cord units (HLA-A2.1.HLA-DR0401)

New York Blood Center, Long Island City, NY, USA $\quad$ n/a

DRAGA mice and SARS-CoV-2 virus

\begin{tabular}{|l|l|l|}
\hline DRAGA mice & WRAIR/NMRC, Silver Spring, MD, USA & n/a \\
\hline SARS-CoV-2 strain USA-WA1/2020 & $\begin{array}{l}\text { via U.S. Centers for Disease Control and Prevention, } \\
\text { BEI Resources NR-52281 }\end{array}$ & batch \#70033175 \\
\hline
\end{tabular}

\begin{tabular}{|l|l|}
\hline Services & \\
\hline Sequencing PCR amplicons & Eurofins, Inc., Coralville, IA, USA \\
\hline Tissue sections from paraffinembedded organs & Histoserv Inc., Germantown, MD, USA \\
\hline H\&E Staining & Histoserv Inc., Germantown, MD, USA \\
\hline Masson's Trichrome staining & Histoserv Inc., Germantown, MD, USA \\
\hline
\end{tabular}

